Article

\title{
Prediction of Layered Thermal Conductivity Using Artificial Neural Network in Order to Have Better Design of Ground Source Heat Pump System
}

\author{
Yanjun Zhang ${ }^{1,2, *}$, Ling Zhou ${ }^{1}$, Zhongjun $\mathrm{Hu}{ }^{1, *}$, Ziwang Yu ${ }^{1}$, Shuren Hao ${ }^{1}$, Zhihong Lei ${ }^{1}$ \\ and Yangyang $\mathrm{Xie}^{1}$ \\ 1 College of Construction Engineering, Jilin University, Changchun 130026, China; \\ zhouling17@mails.jlu.edu.cn (L.Z.); yzw078@163.com (Z.Y.); haosr14@mails.jlu.edu.cn (S.H.); \\ 18943186185@163.com (Z.L.); xieyy16@mails.jlu.edu.cn (Y.X.) \\ 2 Key Laboratory of Groundwater Resource and Environment, Ministry of Education, Jilin University, \\ Changchun 130026, China \\ * Correspondence: zhangyanj@jlu.edu.cn (Y.Z.); Huzj@jlu.edu.cn (Z.H.)
}

Received: 9 May 2018; Accepted: 30 June 2018; Published: 20 July 2018

\begin{abstract}
Ground source heat pumps (GSHPs) have been widely applied worldwide in recent years because of their high efficiency and environmental friendliness. An accurate estimation of the thermal conductivity of rock and soil layers is important in the design of GSHP systems. The distributed thermal response test (DTRT) method incorporates the standard test with a pair of fiber optic-distributed temperature sensors in the U-tube to accurately calculate the layered thermal conductivity of the rock/soil. In this work, in situ layered thermal conductivity was initially obtained by DTRT for four boreholes in the study region. A series of laboratory tests was also conducted on the rock samples obtained from drilling. Then, an artificial neural network (ANN) model was developed to predict the layered thermal conductivity on the basis of the DTRT results. The primary modeling factors were water content, density, and porosity. The results showed that the ANN models can predict the layered thermal conductivity with an absolute error of less than $0.1 \mathrm{~W} /(\mathrm{m} \cdot \mathrm{K})$. Finally, the trained ANN models were used to predict the layered thermal conductivity for another study region, in which only the effective thermal conductivity was measured with the thermal response test (TRT). To verify the accuracy of the prediction, the product of pipe depth and layered thermal conductivity was suggested to represent heat transfer capacity. The results showed that the discrepancies between the TRT and ANN models were $5.43 \%$ and $6.37 \%$ for two boreholes, respectively. The results prove that the proposed method can be used to determine layered thermal conductivity.
\end{abstract}

Keywords: distributed thermal response test; thermal conductivity; laboratory test; artificial neural network; ground source heat pump

\section{Introduction}

Increasing energy consumption, particularly the burning of fossil fuels, has resulted in global air pollution and environmental degradation, and geothermal sources have attracted increasingly more attention as a renewable resource [1-3]. Ground source heat pumps (GSHPs), one of the most important ways to use geothermal energy, have been widely used in recent years owing to their advantages of high efficiency, energy savings, and environmental protection [4-7]. GSHPs use ground source energy as the cooling source for cooling buildings in summer and the low-temperature heat source for heating buildings in winter [8]. The main part of the GSHP system design is the ground heat exchanger (GHE), which is responsible for a major portion of the initial cost of this system [9]. The performance of GHE is 
influenced by many factors, with the most important one being the ground thermal conductivity around GHE $[10,11]$ (thermal conductance is the quantity of heat that passes in unit time through a plate of unit area and thickness when its opposite faces differ in temperature by one kelvin, and defines the units as $\mathrm{W} /(\mathrm{m} \cdot \mathrm{K}))$. Two methods are available to measure GHE performance: laboratory experiments and thermal response test (TRT) methods [12-15]. Laboratory experiments test the thermal parameters of rock and soil samples collected at the test site using a steady- or non-steady-state heat flow method. This method can test the thermal conductivity of each layer of different soil and rock types. However, considering that the disturbance of soil or rock mass during the sampling process causes larger measurement errors, the resulting parameters cannot be directly applied to the GSHP design. The TRT method for GHE was first proposed by Mogensen [16], and is referred to as "the standard TRT" in the current study. The standard TRT simulates the actual operation of the project by cooling or heating a cycle medium at a constant power, and records the inlet and outlet fluid temperature variations during the test period. The standard TRT obtains comprehensive in situ borehole thermal parameters by analyzing the temperature data based on the line heat source model [17]. It is widely used in the actual projects.

The complexity of underground aquifers and the randomness of the geothermal characteristics of different layers greatly influence ground thermal conductivity. The accurate measurement of the thermal conductivity of rock and soil layers is one of the key points in the scientific application of GSHP technology, which is important in calculating heat transfer capacity, optimizing GHE length, and reducing initial investments [18]. However, the standard TRT has a limitation in that it only provides an effective ground thermal conductivity for GSHP design, but cannot calculate the layered thermal conductivity [19]. In recent years, many researchers have attempted to find ways to calculate the layered thermal conductivity. Fujii et al. [20] first proposed a distributed thermal response test (DTRT) based on a distributed temperature sensing (DTS) system in 2006. In 2009, they measured the temperatures with the fiber-optic DTS in the GHE and used the least squares method to estimate the depth-change thermal conductivity [21]. Acuña et al. [22] applied fiber-optic distributed temperature sensors (DTSs) in U-tubes and analyzed the ground thermal conductivity and borehole thermal resistance of each $20 \mathrm{~m}$ thick sub-layer. DTRT is the modification to the standard TRT. A pair of fiber-optic DTSs was added to the standard TRT and then inserted into the pipe of the GHE to measure the temperature variations of the fluid from the surface to the underground in real time. The schematic diagram of DTRT is shown in Figure 1. A mathematical model for the layered thermal properties in each sub-layer was established individually based on the linear heat source heat transfer model, which can calculate the layered thermal conductivity of the rock/soil. It can not only establish the layered heat transfer model more accurately and improve the accuracy of calculation of the heat transfer model, but also effectively use the formation with better heat exchange capacity and improve geothermal utilization.

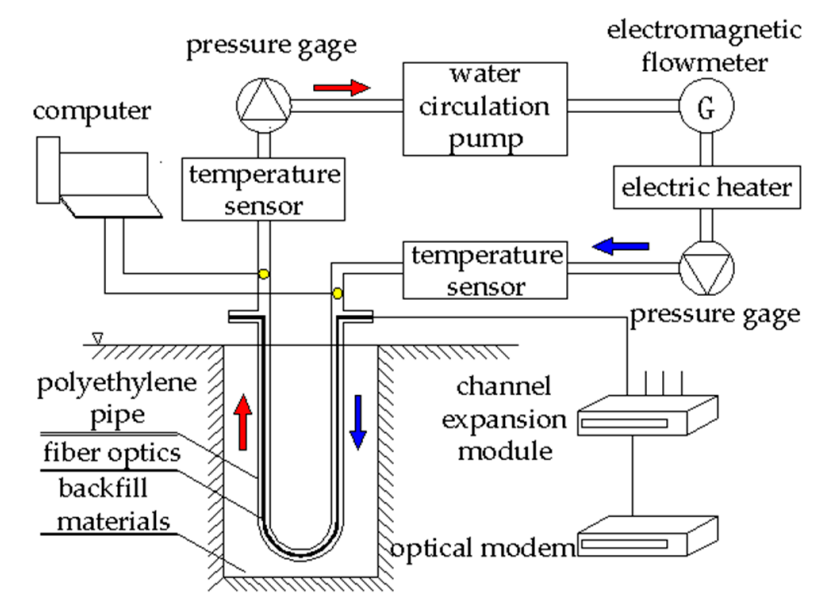

Figure 1. Schematic diagram of the ground source heat pumps (GSHP) system in distributed thermal response test (DTRT). 
Many factors affect thermal conductivity, including mineral variety, particle size, porosity, density, water content, and permeability [23-26]. Therefore, it can be considered to establish a model to predict the layered thermal conductivity based on the main influential factors. Zhang et al. [13] used the analytic hierarchy process (AHP) to modify the thermal physical parameters of a laboratory test as replacements or supplements to the standard TRT results, in which the criterion layer consists of layer depth, water content, density, and permeability. Gao et al. [11] and Zhang et al. [27] studied the correlation of shallow layer rock and soil thermal physical tests in the laboratory and field and tried to inverse the comprehensive thermal conductivity of a borehole through the AHP method. However, the subjectivity of AHP is strong. The establishment of the structural model and the construction of the judgment matrix are decided by the subjective judgment of the decision makers. This case usually leads to errors if problems are incomprehensive. Moreover, AHP is too rough to be suitable for solving high-precision problems. The ANN model may be a good candidate for estimating layered in situ thermal conductivity, because it has been widely used in prediction, classification, pattern recognition, and function approximations. Furthermore, it can solve complex problems in actual situations with the advantages of learning capability, memory simulation, and nonlinear approximation $[28,29]$.

ANN has been used widely in the energy system. Esen et al. predicted the performance of a GSHP system with vertical and horizontal GHEs on the basis of ANN. They also used several methods such as an adaptive neuro-fuzzy inference system, support vector machine, and ANN for predicting of the performance of GSHP systems. The results showed that the ANN model was highly accurate when predicting the system coefficient of performance [30-33]. Fannou et al. [34] used an ANN model to predict the performance of a direct expansion heat pump. Gang et al. $[35,36]$ used ANN to predict the water temperature exiting to control the parallel-connection hybrid GSHP system with an intermittent run of the GHEs. Sang et al. [37] used multiple linear regression analysis and ANN models to research the quantitative analysis of the influencing variables on large-scale and GSHP system performance and the hourly performance prediction for application as a baseline for accurate cost-saving calculation by energy conservation measures in an hourly electricity pricing system. However, studies on the prediction of layered thermal conductivity with ANN have not yet be done.

In this study, the DTRT experiment and the laboratory tests with the samples obtained from the same borehole were all conducted in Changchun City, Jilin Province, China. The findings on layered thermal conductivity calculated with the two methods are compared in order to determine the main influencing factors. Then, the influencing factors are utilized as the input layer parameters to build the ANN models and predict the layered thermal conductivity of GSHP. This method enables the predicted data to reflect the capacity of the ground heat conduction as close as possible to that of DTRT. This method also depicts the layered thermal conductivity in the standard TRT test area and optimizes the GSHP system design.

\section{Formation Characteristic of the Test Area}

Changchun City is in Northwest Jilin Province, China, and is the capital of the province. The geographic coordinates are longitude of $124^{\circ} 18^{\prime} \mathrm{E}-127^{\circ} 05^{\prime} \mathrm{E}$ and latitude of $43^{\circ} 05^{\prime} \mathrm{N}-45^{\circ} 15^{\prime}$ N. Changchun belongs to the north temperate zone continental monsoon climate with four seasons. This area is a cold climate zone. The region's annual average temperature is $4.8^{\circ} \mathrm{C}$, with a maximum temperature of $39.5{ }^{\circ} \mathrm{C}$ and a minimum temperature of $-39.8^{\circ} \mathrm{C}$ [38].

The two field test areas in this study are located in Chaoyang District, southwest of Changchun City, and they are marked in red in Figure 2. DTRT was conducted in the CY01 study region, which had four boreholes (ZK01, ZK02, ZK03, and ZK04), while the standard TRT was conducted in the CY02 study region, which had two boreholes (ZK05 and ZK06). All six boreholes are $120 \mathrm{~m}$ deep. All GHEs utilize single-U pipes. 


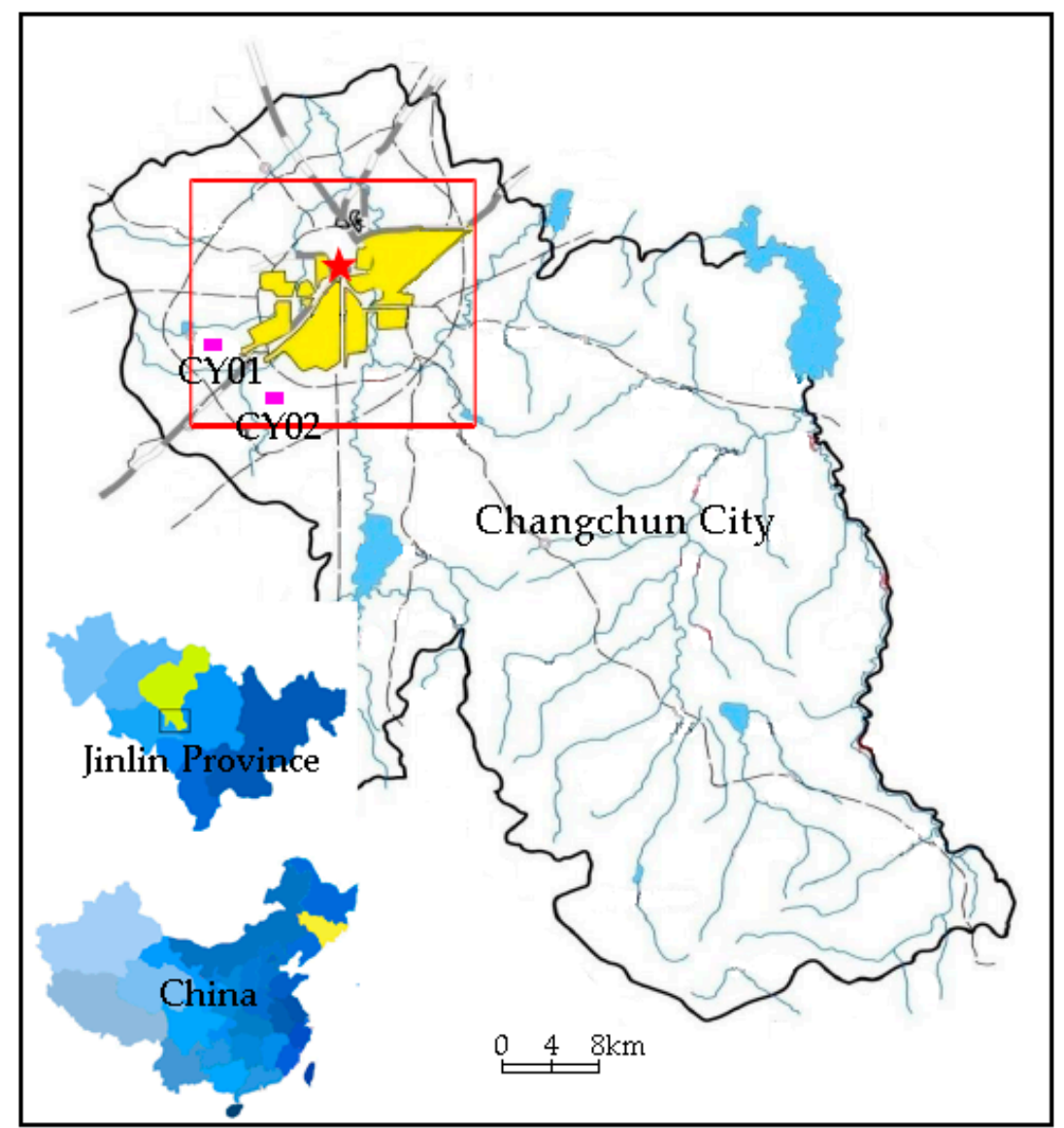

Figure 2. Study region location.

According to the borehole lithology data, the strata mainly consist of silty clay, mudstone, sandstone, silty mudstone, and fine sandstone. The geological layers of the ground within $120 \mathrm{~m}$ depth are divided into nine layers. The geological profile of the borehole field is shown in Figure 3. In $0.7-19.6 \mathrm{~m}$, it is composed of silty clay, and unconfined aquifer is revealed in this layer. The layer from 19.6-49.2 $\mathrm{m}$ is the impermeable layer, which is the crust of weathering at the top of the Lower Cretaceous impermeable layers that are composed of mudstone. The layer from $49.2-120 \mathrm{~m}$ is confined aquifer, which is mainly the interbeds of sandstone, silty mudstone, and fine sandstone in different thicknesses. The measured groundwater level is $1.5 \mathrm{~m}$ during the exploration period. The respective permeability coefficient values of the clay layer and the sandstone layers are $0.2-0.4$ and $1.5-3.8 \mathrm{~m} / \mathrm{d}$, respectively, according to the engineering experience in Changchun area. 


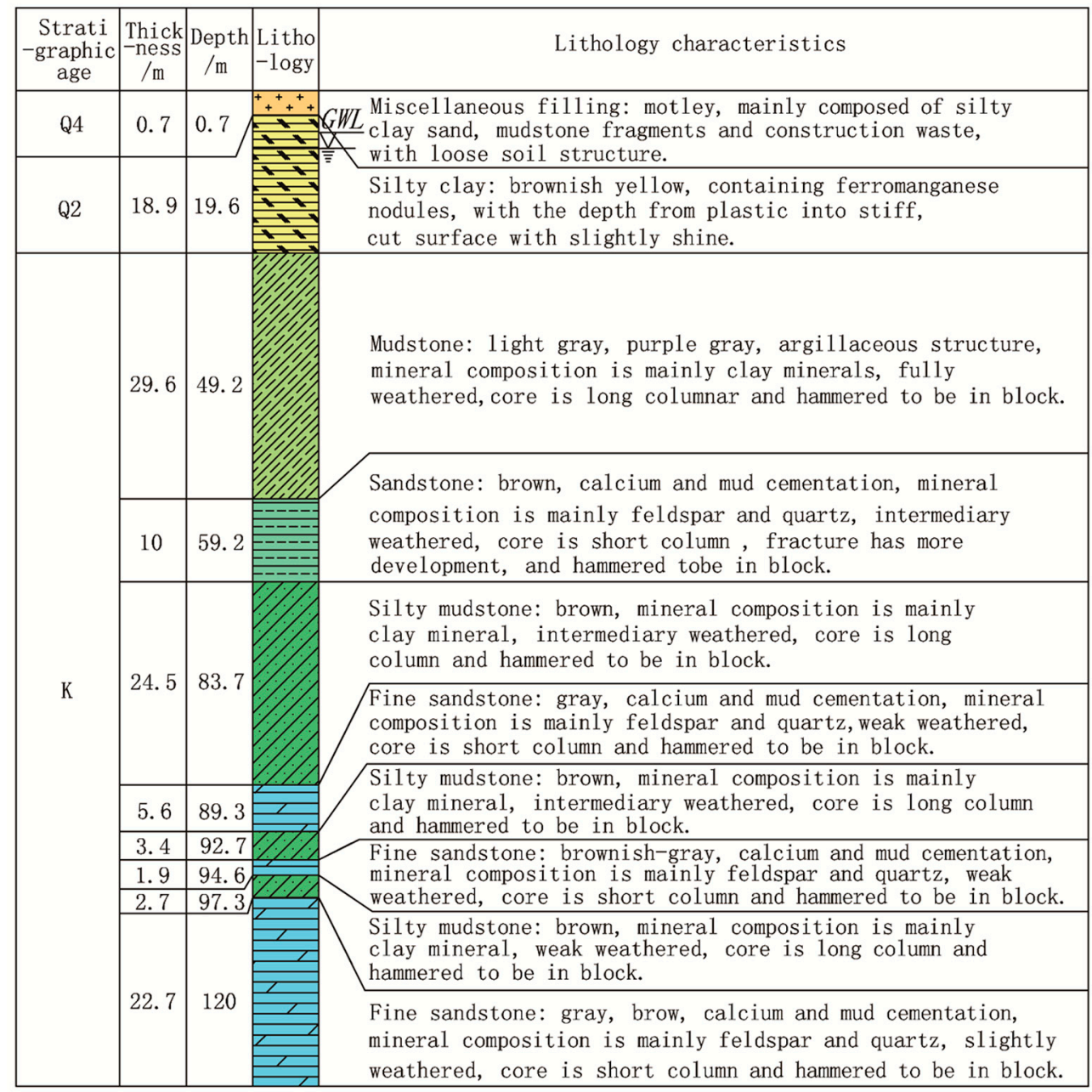

Figure 3. Comprehensive strata log diagram.

Determining the initial ground temperature before conducting the standard TRT and DTRT is important. The temperature profiles measured in the borehole are shown in Figure 4. The depth of the changing temperature layer is $0-20 \mathrm{~m}$. The depth of the constant temperature layer is $20-40 \mathrm{~m}$, and the mean temperature is $7.8^{\circ} \mathrm{C}$. The depth at which temperature begins to increase is $40-120 \mathrm{~m}$, and the geothermal gradient is approximately $3^{\circ} \mathrm{C} / 100 \mathrm{~m}$. The initial mean temperature of each borehole is obtained by the weighting method. The average temperature is $8.6^{\circ} \mathrm{C}$ over the entire range of the ground within $120 \mathrm{~m}$, except for the changing temperature layer. 


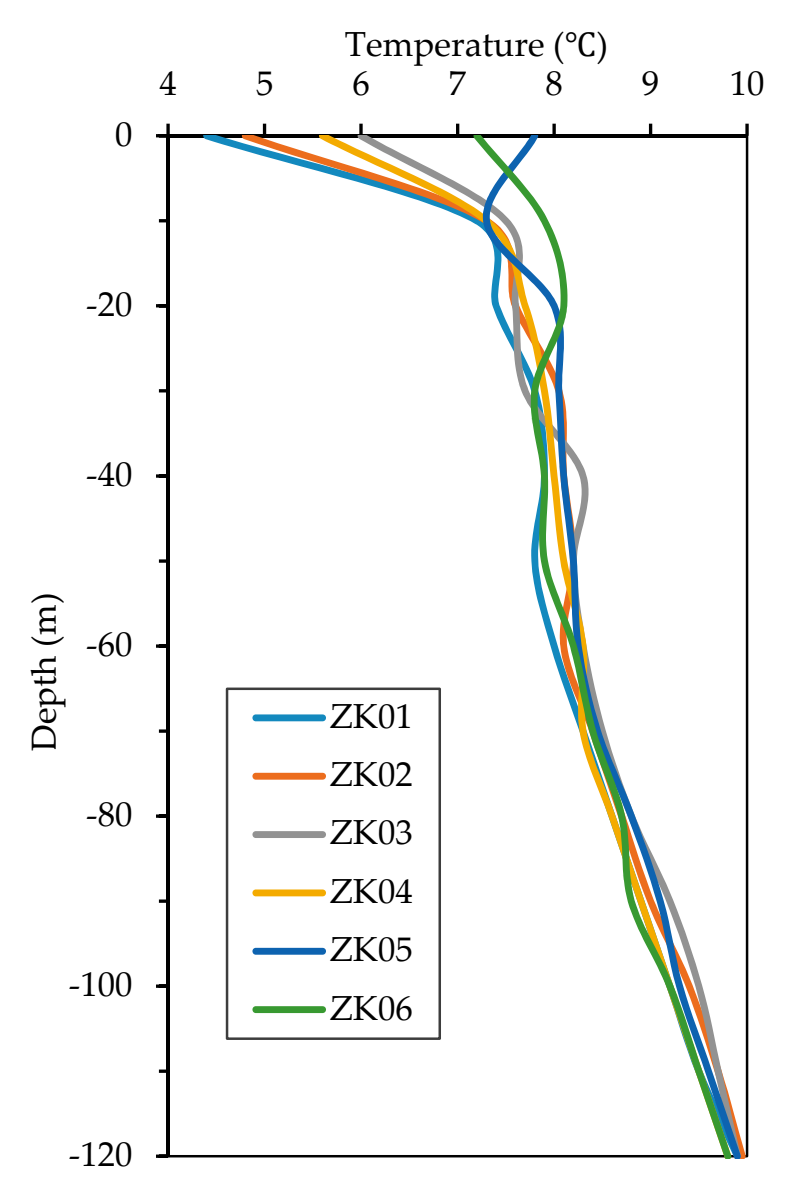

Figure 4. Temperature profiles along different boreholes.

\section{Project Example 1}

\subsection{Project Overview of CY01 Study Region}

The CY01 field test area is approximately $40,000 \mathrm{~m}^{2}$. To apply GSHP, DTRT was performed for each borehole with $6.0 \mathrm{~kW}$ heating power. The entire experiment experienced a $48 \mathrm{~h}$ heating period [12], which followed the China Geological Survey Specification.

To obtain more detailed characteristics of ground thermal properties before conducting the DTRT, samples were taken once every $2 \mathrm{~m}$, according to the relative specification requirement. Sixty samples of soil and rock were collected from every borehole, and 240 samples were tested in the laboratory. Thermal physical parameters such as thermal conductivity and specific heat capacity and physical parameters such as natural rock density, porosity, and water content were obtained in detail. In this work, the thermal conductivity scanning instrument developed by Popov et al. [39] is selected for the measurements. This instrument is a kind of unsteady method based on the moving point heat source method, and it offers the advantages of high accuracy, precision, and efficiency. It also does not cause damage to a specimen, and its measurement error is less than $1 \%$ in order to reduce the disturbance for the samples, especially the water content. Hence, the sample was sent to the laboratory as soon as possible after sampling, and it was sealed well during transportation. The number of samples for each test was more than five, in order to ensure accuracy of the results.

In this test, the experimental equipment was composed of the standard TRT equipment and fiber-optic DTS. The equipment for TRT is the GSHT-1 geotechnical in situ thermophysical property tester that is certified by the China Geological Survey. The fiber-optic DTS is widely used in the GHE system because of its low signal loss and small diameter, which can avoid disturbing the flow circulation [40]. The principle of DTS is the laser back-scattering Raman effects [41]. The DTS inserted 
into the inner part of the U-type tube was used to monitor the temperature evolution of the ground along the depth. Owing to the precision of the DTS, the temperature change was very small when the distance between the optical fiber temperature acquisition points was very short in the buried tube, and the DTS could not accurately measure the temperature change. Figure 5 shows the 14 temperature collection points selected according to the change of the stratum lithology. Three of the optical fiber temperature acquisition points were in the quaternary silty clay layer at depths of 6,12 , and $18 \mathrm{~m}$. The rest of the optical fiber temperature acquisition points were distributed vertically along the borehole at intervals of approximately $10 \mathrm{~m}$. During the test, a constant heating power of $6000 \mathrm{~W}$ was maintained and the circulating pump was used to drive the hot water to flow at a speed of $1 \mathrm{~m}^{3} / \mathrm{h}$ in the buried pipe to dissipate the heat into the soil. The temperature of recycled fluid in GHE was recorded by the DTS with a temporal interval of $60 \mathrm{~s}$. In addition, the fluid temperatures at both shanks of the U-tube were measured by the temperature probe.

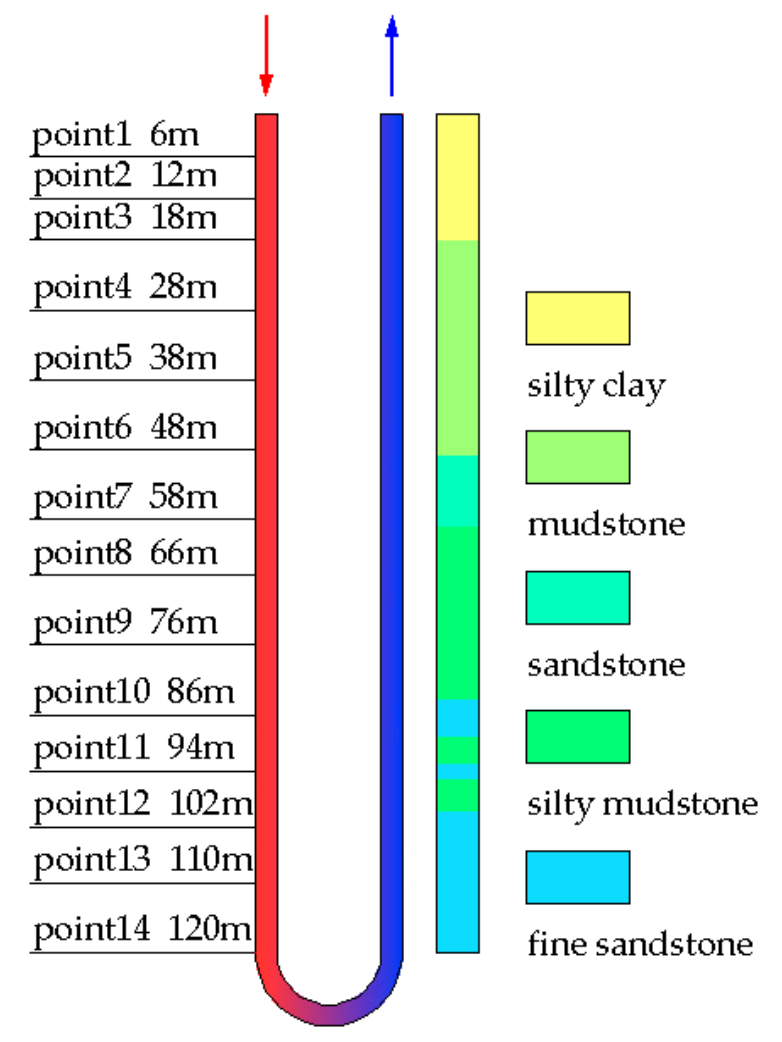

Figure 5. Schematic measurement setup diagram of the DTRT.

The vertical temperature profiles of ZK01 at the initial and the 3rd, 6th, 12th, 24th, and 48th h, according to the data measured by the DTS, are plotted in Figure 6. Based on the distributed temperature curve and the known input heating power, the line heat source model was used to calculate the thermal conductivity of each sublayer. The layered thermal conductivity values obtained by the DTRT and laboratory tests are shown Figure 7. Besides, the changing curves of the physical properties of boreholes ZK01-04 with depths are also drawn in Figure 7.

The average layered thermal conductivity values obtained by DTRT are $0.979,1.768,2.106,2.042$, and $2.313 \mathrm{~W} /(\mathrm{m} \cdot \mathrm{K})$ for silty clay, mudstone, sandstone, silty mudstone, and fine sandstone, respectively. The average layered thermal conductivity values obtained by the laboratory are $0.520,1.358,1.647$, 1.837 , and $1.915 \mathrm{~W} /(\mathrm{m} \cdot \mathrm{K})$ for silty clay, mudstone, sandstone, silty mudstone, and fine sandstone, respectively. The results showed that the thermal conductivity varies with the layer conditions, and the measured layered thermal conductivity by DTRT is greater than that by the laboratory. The discrepancy is mainly caused by the changes in water content and space environment during sampling, especially 
the groundwater seepage. For the silty clay, sandstone, and fine sandstone, the discrepancy between the results of the laboratory and field tests is estimated to be because of the existence of groundwater flow. The respective permeability coefficient values of the clay layer and the sandstone layers are $0.2-0.4$ and $1.5-3.8 \mathrm{~m} / \mathrm{d}$, respectively, according to the engineering experience in Changchun area. The heat is convected by the flow of groundwater, leading to higher conductivity of this layer. In addition, the change of water content may also contribute to the discrepancy of the field and laboratory test results. Zhang et al. [9] found the average thermal conductivity of natural flow field is $23 \%$ higher than the laboratory experiment weighted results and acceleration of groundwater flow is propitious to improve the thermal conductivity. For the mudstone and silty mudstone, the discrepancy between the results of the two kinds of tests is relatively small, and the main factor resulting in the difference is estimated to be the moisture change during the sampling process.

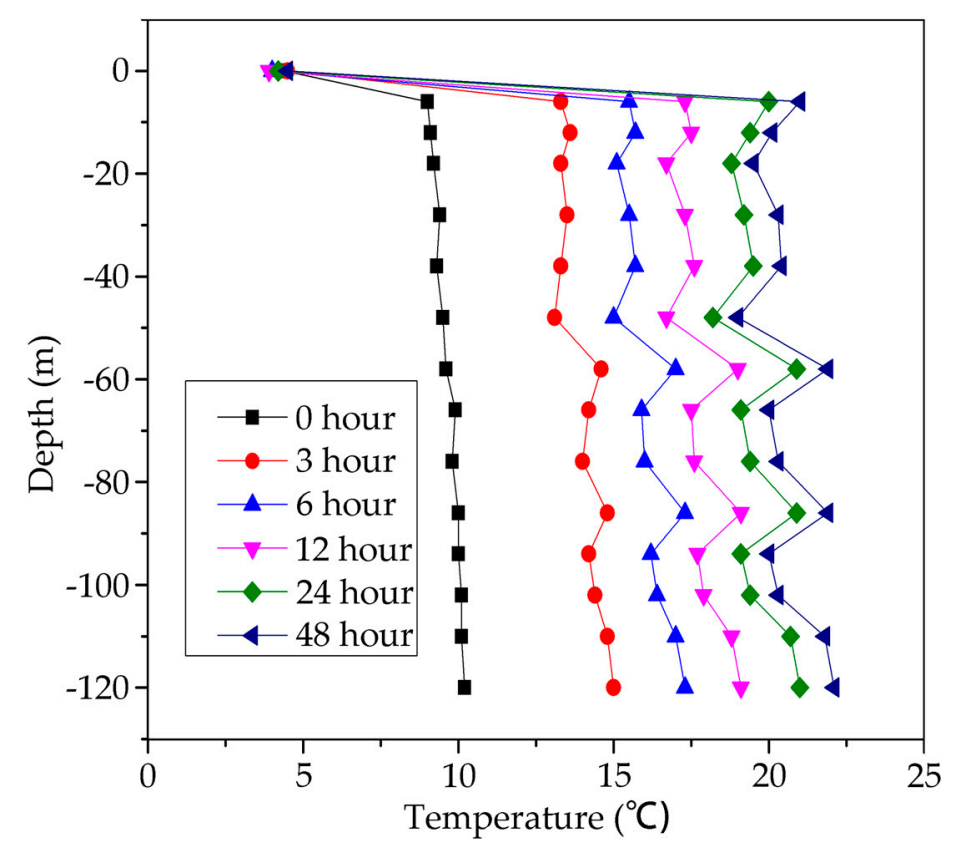

Figure 6. Temperature profile recorded during the heating process in the borehole by the DTRT.

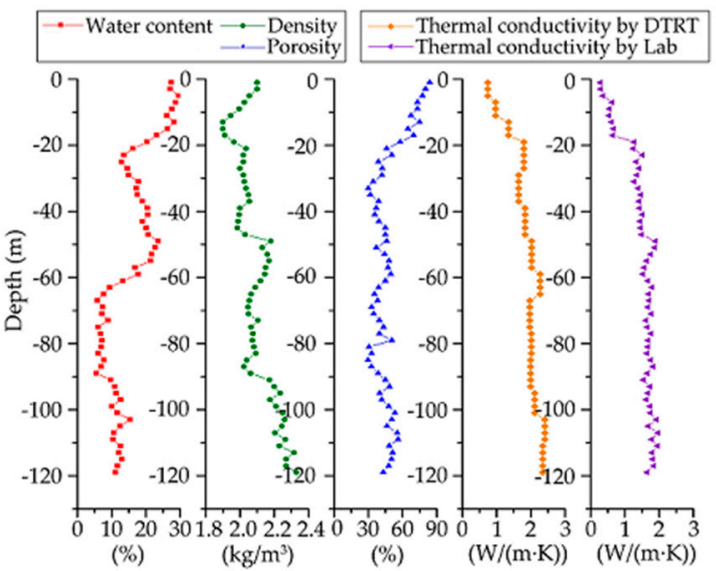

(a)

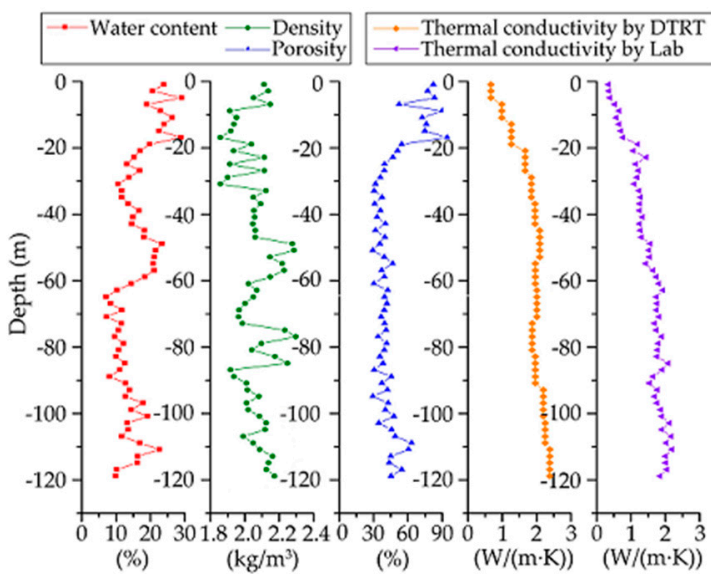

(b)

Figure 7. Cont. 


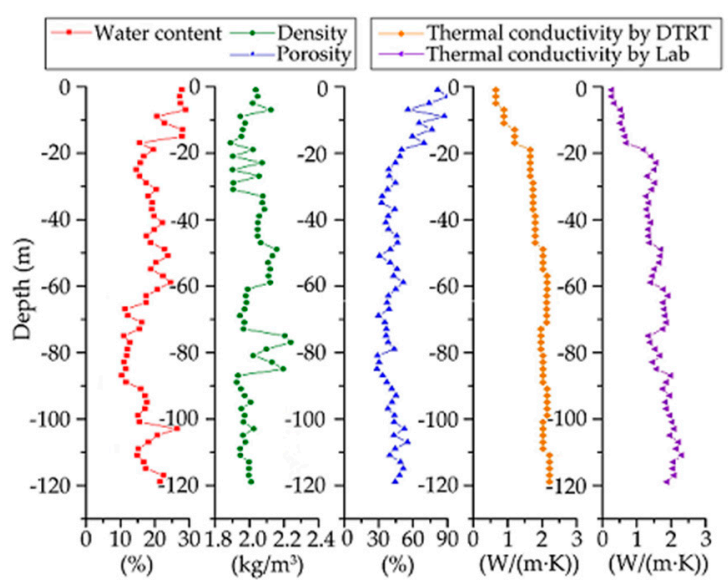

(c)

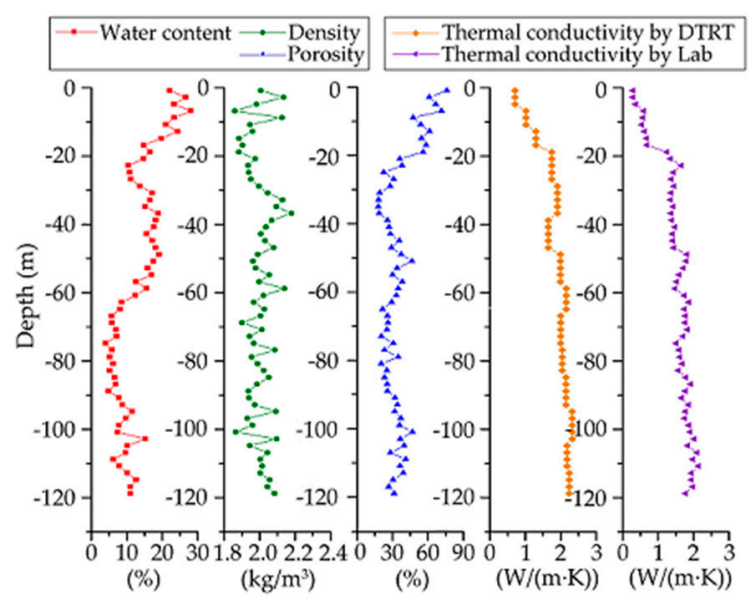

(d)

Figure 7. Testing results of the laboratory tests and the DTRT. Clockwise from top left: (a) ZK01, (b) ZK02, (c) ZK03, and (d) ZK04.

Cho et al. [24,25] found that the thermal conductivity of dry samples decreases with the increase of effective porosity, and the thermal conductivity of wet samples increases with the increase of water content, because the lower thermal conductivity of air in voids of rock is replaced by the higher thermal conductivity of water. Under saturated conditions, all pores of granite are filled with water, which decreases the effects of effective porosity on thermal conductivity under saturated conditions. Abu-Hamdeh et al. [42] found that the change of water content has a great influence on the thermal properties of rock and soil when the water content is low, and the influence is related to density. Abuel-Naga et al. [43] found that thermal conductivity increases with increasing soil density by investigating the thermal conductivity of soft Bangkok clay from laboratory and field measurements. The analyses revealed that the main factors influencing the conductivity results are water content, porosity, and density. Therefore, a new method is proposed in which the ANN models are used to predict the layered thermal conductivity based on the result data of DTRT.

\subsection{Artificial Neural Network}

ANN is an information processing technology that is inspired by the way of biological nervous systems. It can solve complex problems in actual situations with the advantages of learning capability, memory simulation, and nonlinear approximation [28,29]. In the present study, a new method is proposed in which an ANN model is used to predict the layered thermal conductivity based on primary influential factors, namely, natural density, moisture content, and porosity. This method enables the predicted data to reflect the ground heat conduction capacity as close as possible to that of the DTRT.

ANNs have different types. One of the most widely used is the back propagation (BP) ANN, which was first introduced by McClelland and Rumelhart in 1986 [44]. A BP ANN is a multi-layer feedforward neural network trained by the error back-propagation learning algorithm. The basic structure of the BP ANN model is composed of input, hidden, and output layers. A typical neural network is shown in Figure 8. Before BP ANN can be used, the network must be trained to have associative memory and prediction capability. The training process includes the following steps. 


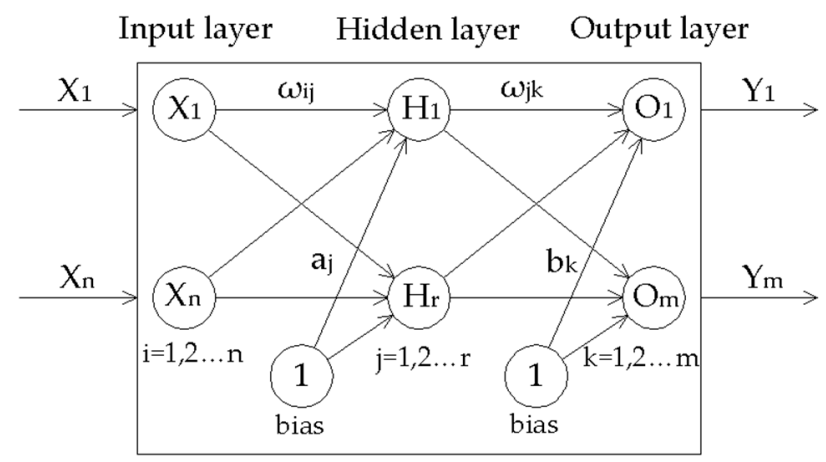

Figure 8. Typical neural network.

First, determine the number of neurons in the input, hidden, and output layers based on sample data and randomly assign the initial values of the weights. Then, use the following equations [Equations (1) and (2)] to calculate the hidden layer and output layer value, respectively.

$$
\begin{aligned}
& H_{j}=f\left[\sum_{i=1}^{n}\left(x_{i} \omega_{i j}\right)-a_{j}\right] \quad j=1,2, \ldots, r \\
& O_{k}=f\left[\sum_{j=1}^{r} H_{j} \omega_{j k}-b_{k}\right] \quad k=1,2, \ldots, m
\end{aligned}
$$

where $\omega_{i j}$ is the weight between the input and hidden neurons, $\omega_{j k}$ is the weight between the hidden and output neurons, $x_{i}$ is the value of the input, $n$ is the number of input neurons, $H_{j}$ is the value of the output for hidden nodes, $r$ is the number of neurons of the hidden layer, $O_{k}$ is the value of the output for output nodes, $m$ is the number of neurons of the output layer, $a_{j}$ is the bias weight between the input and hidden neurons, and $b_{k}$ is the bias weight between the hidden and output neurons.

$f$ refers to the activation function. The logsig function [Equation (3)] and the purelin function [Equation (4)] are the activation functions for the hidden and the output layers in this study.

$$
\begin{gathered}
\log \operatorname{sig}(x)=\frac{1}{1+e^{-x}} \\
\operatorname{purelin}(x)=x
\end{gathered}
$$

After the output value is determined, the error term for each node is computed by Equation (5). Finally, the new values of the weights are obtained by the following equations.

$$
\begin{gathered}
e_{k}=Y_{k}-O_{k} \quad k=1,2, \ldots, m \\
\omega_{i j}=\omega_{i j}+\eta H_{j}\left(1-H_{j}\right) x(i) \sum_{k=1}^{m} \omega_{j k} e_{k} \quad i=1,2, \ldots, n ; \quad j=1,2, \ldots, r \\
\omega_{j k}=\omega_{j k}+\eta H_{j} e_{k} \quad j=1,2, \ldots, r ; \quad k=1,2, \ldots, m \\
a_{j}=a_{j}+\eta H_{j}\left(1-H_{j}\right) \sum_{k=1}^{m} \omega_{j k} e_{k} \quad j=1,2, \ldots, r \\
b_{k}=b_{k}+e_{k} \quad k=1,2, \ldots, m
\end{gathered}
$$

where $e_{k}$ is the prediction error, $Y_{k}$ is the expected value, and $\eta$ is the learning rate. These procedures are repeated until the desired value of error is achieved. 


\subsection{Modeling of Layered Thermal Conductivity with ANN}

According to the geological conditions and test results of the Changchun CY01 study region, five BP neural network models were established to predict the layered thermal conductivity for layers 1 to 5. The structure and algorithm of ANN models are introduced as follows.

(1) Input layer

The input layer includes three nodes that represent the three influential factors of thermal conductivity: water content, porosity, and density.

(2) Output layer

The output layer includes one node that is the layered thermal conductivity obtained by the DTRT.

(3) Hidden layer

The selection of the number of hidden layer nodes directly affects the performance of the BP neural network. One empirical formula is frequently used, which is shown as Equation (10) [45].

$$
r=2 n+1
$$

where $r$ is the number of neurons of the hidden layer, and $n$ is the number of input neurons. Consequently, the hidden layer has seven neurons. The schematic diagram is shown in Figure 9.

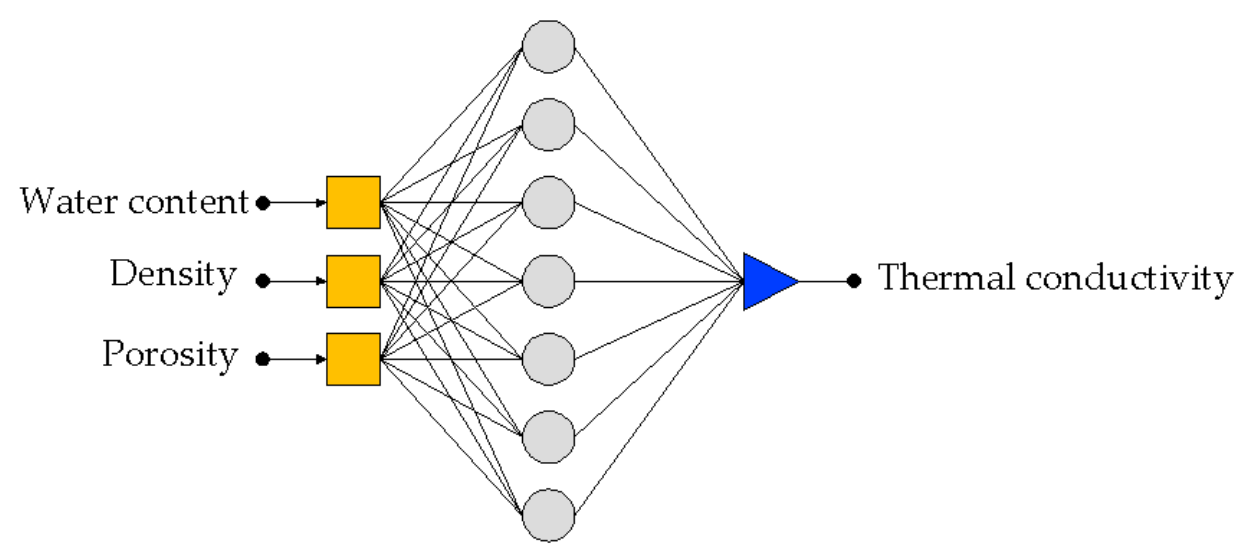

Figure 9. Network architecture of the artificial neural network (ANN) model for predicting thermal conductivity.

(4) Learning algorithms

BP networks have various kinds of learning algorithms, and it is difficult to determine which one is optimal for a given problem. It is usually chosen by trial and error, which is also adopted in this paper. The root mean squared error (RMS) can be used to estimate the performance of the learning algorithms in this paper. The values are determined using the following equation, Equation (11).

$$
R M S=\sqrt{\frac{\sum_{i=1}^{N}\left(\lambda_{\text {test }, i}-\lambda_{\text {pre }, i}\right)^{2}}{N}}
$$

where $\lambda_{\text {pre, } i}$ is the calculated value, $\lambda_{\text {test }, i}$ is the testing value, and $N$ is the number of samples.

Four learning algorithms are used in this study, including Levenberg-Marquardt (LM), one-step secant (OSS), scaled conjugate gradient (SCG), and Broyden-Fletcher-Goldfarb-Shanno (BFGS), to determine the optimal value. In the MATLAB toolbox, they are called trainlm, trainoss, trainscg, and trainbfg, respectively. 
(5) Training and testing samples

The influence of density, porosity, and moisture content on the thermal conductivity of rock soil varies for different stratigraphic types. In this study, five ANN models are established according to the stratigraphic types of the CY01 field test area. The 240 group datasets from the ZK01, ZK02, ZK03, and $Z K 04$ boreholes are divided into training, validation, and test sets. The 180 sets of test data of the $\mathrm{ZK} 01, \mathrm{ZK} 02$, and ZK03 are used as training and validation sets, in which the training set is assigned to be $70 \%$. The verification set is assigned to be $30 \%$, and the 60 group test data of the ZK04 are used as the test set. The details of the selection of the training and testing samples for the five cases are given in Table 1. The role of the training sets is to train the network. The role of the validation sets is to prevent overfitting of the training sets. Validation sets are usually used with training sets. The role of the test sets is to determine the model performance.

Table 1. Artificial neural network (ANN) models under different cases.

\begin{tabular}{lcc}
\hline Name & Training and Validation Samples & Testing Samples \\
\hline Case 1 & silty clay of ZK01, ZK02, ZK03 borehole & silty clay of ZK04 borehole \\
Case 2 & mudstone of ZK01, ZK02, ZK03 borehole & mudstone of ZK04 borehole \\
Case 3 & sandstone of ZK01, ZK02, ZK03 borehole & sandstone of ZK04 borehole \\
Case 4 & silty mudstone of ZK01, ZK02, ZK03 borehole & silty mudstone of ZK04 borehole \\
Case 5 & fine sandstone of ZK01, ZK02, ZK03 borehole & fine sandstone of ZK04 borehole \\
\hline
\end{tabular}

\subsection{Results of ANN Models of Layered Thermal Conductivity}

ANN models in this paper are all performed using the neural network toolbox under the MATLAB environment. All inputs and outputs are normalized to the interval $(0,1)$ to ensure that no special factor is dominant over the others. Four learning algorithms (LM, OSS, SCG, and BFGS) are used to train and verify the five models (Cases 1-5) in the study. The results are shown in Figure 10. All the RMSs of training and validation are small, less than 0.07. SCG and BFGS algorithms have similar RMSs. Models with the OSS algorithm perform better than those with SCG and BFGS with smaller RMSs. LM performs better than OSS, and all RMSs of LM models are smaller than those in OSS models. LM can achieve the smallest training and validation RMSs.

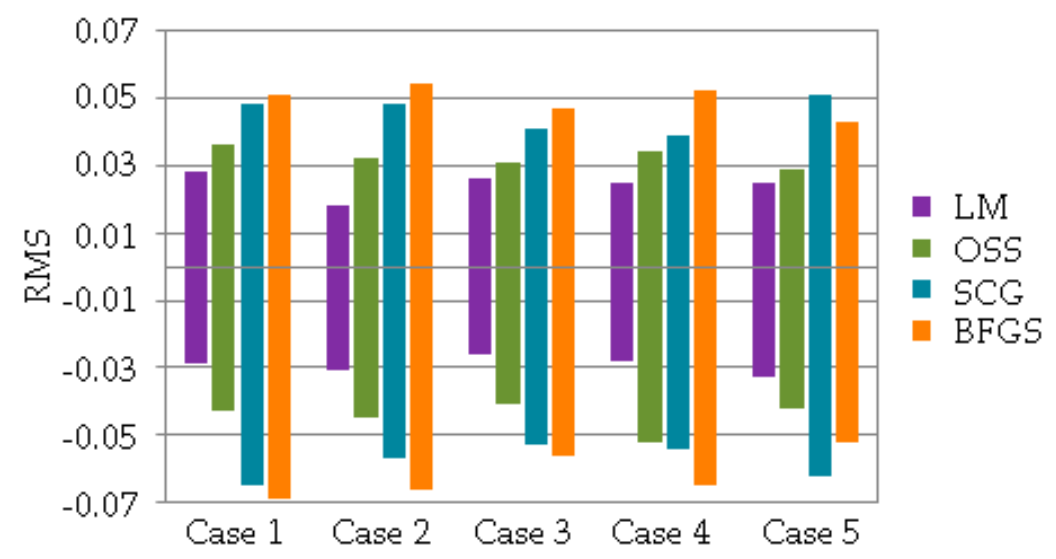

Figure 10. Results of root mean squared errors (RMS) with different learning algorithms. LMLevenberg-Marquardt; OSS-one-step secant; SCG-scaled conjugate gradient; BFGS-Broyden-Fletcher-Goldfarb-Shanno. 
The prediction accuracy is measured using three statistical methods: the coefficient of determination $\left(R^{2}\right)$, RMS, and mean absolute percentage error (MAPE). These values are determined using the following equations.

$$
R^{2}=1-\frac{\sum_{i=1}^{N}\left(\lambda_{\text {test }, i}-\lambda_{\text {pre }, i}\right)^{2}}{\sum_{i=1}^{N}\left(\lambda_{\text {pre }, i}-\bar{\lambda}_{\text {pre }, i}\right)^{2}}
$$

where $\bar{\lambda}_{\text {pre, } i}$ is the mean of the calculated value.

$$
M A P E=\frac{1}{N} \sum_{i=1}^{N}\left|\frac{\lambda_{\text {test }, i}-\lambda_{\text {pre }, i}}{\lambda_{\text {pre }, i}}\right| \times 100
$$

Water content, porosity, and density are used as the input parameters; layered thermal conductivity is used as the output parameters; and LM is used as the learning algorithm, which is chosen as the best network. The calculated results of MAPE, RMS, and $\mathrm{R}^{2}$ values of the training, validation, and test sets are summarized in Table 2 . The results show that the average MAPE values are 1.496, 1.879, and 2.006. The corresponding RMS average values are 0.0244, 0.0294, and 0.0410. The corresponding $\mathrm{R}^{2}$ average values are $0.9572,0.9348$, and 0.9096 . The results show that the thermal conductivity is predictable, and the accuracy of the prediction is acceptable.

The estimated thermal conductivity by ANN models against the testing thermal conductivity for each layer is displayed in Figure 11. The bisectrix drawn with a dotted line represents equal values of the experimental and the predicted thermal conductivity. The solid lines are the regression lines of all datasets consisting of training and test datasets. The slopes of the regression line are obtained as $0.9868,0.9116,0.9716,0.9362$, and 0.9176 for Cases $1-5$, respectively, which are all greater than 0.9 . This result indicates that the training quality of the model is very good, and no serious inaccuracy or wrong samples are noted. 


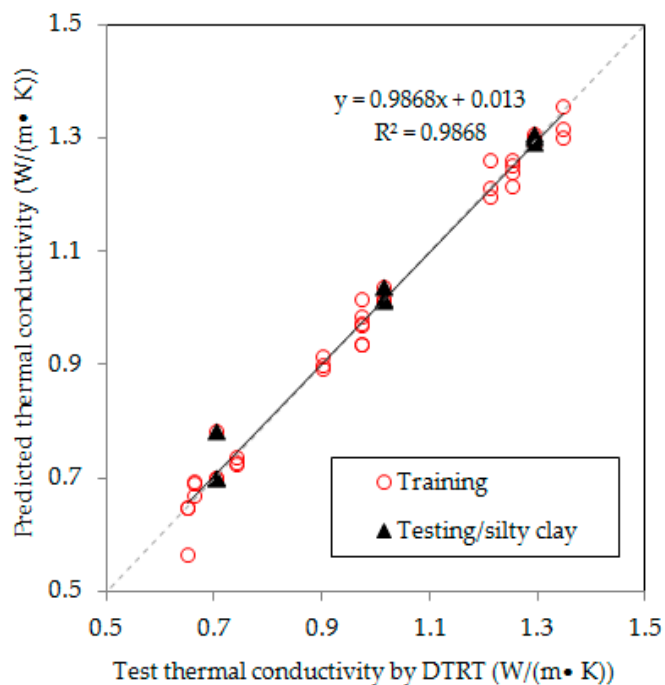

(a)

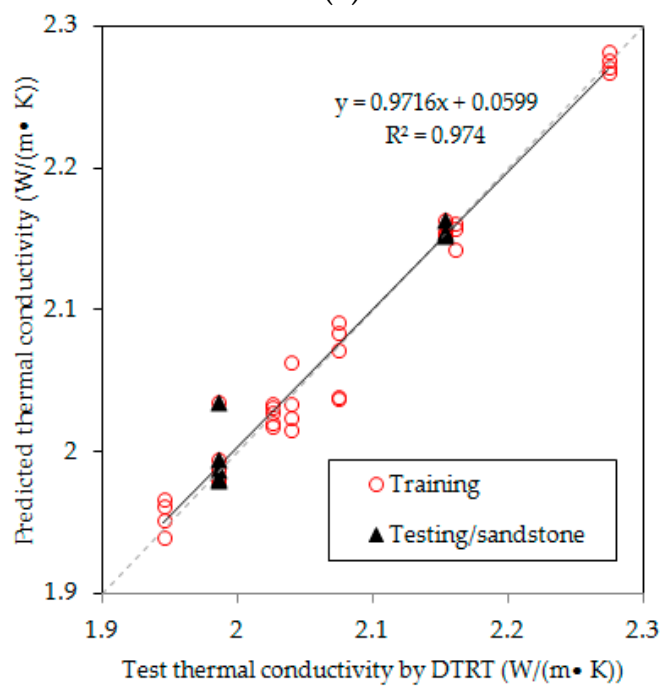

(c)

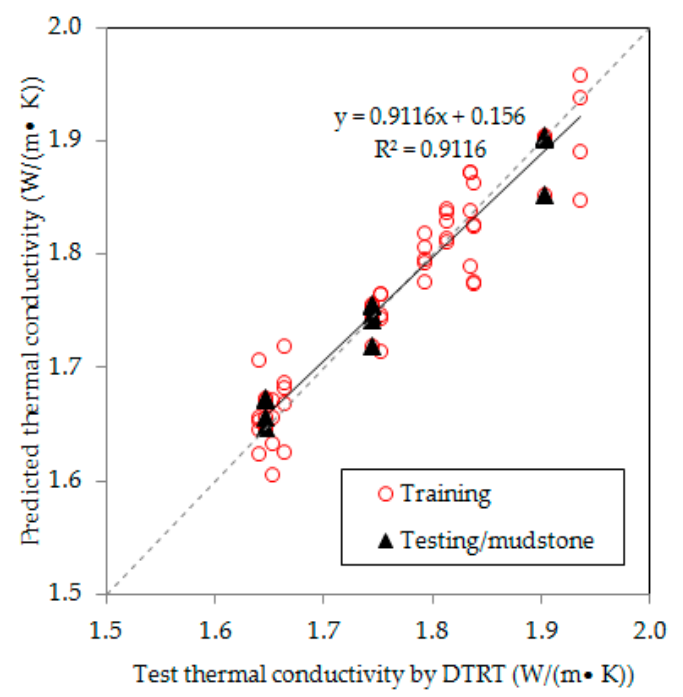

(b)

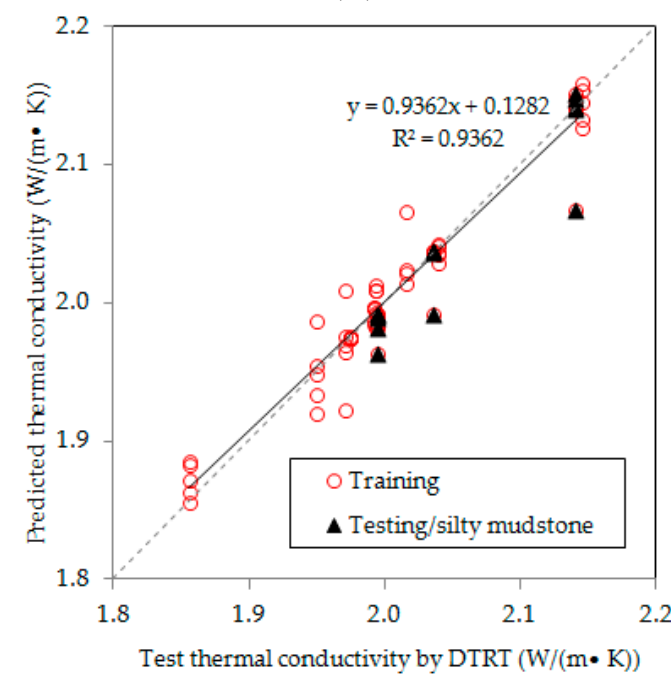

(d)

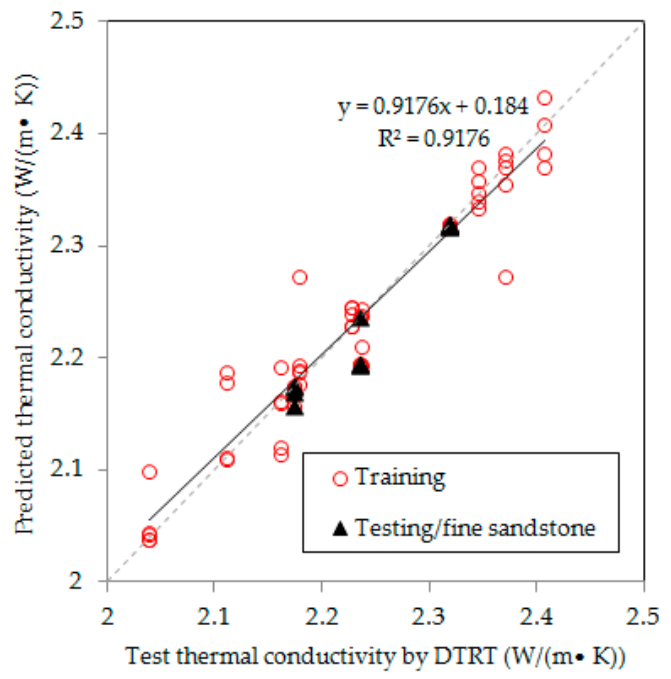

(e)

Figure 11. Correlation of experimental and predicted layered thermal conductivity, (a) silty clay, (b) mudstone, (c) sandstone, (d) silty mudstone, (e) fine sandstone. $\mathrm{R}^{2}$ —coefficient of determination. 
Table 2. Prediction indices for training networks. RMS—root mean square; $\mathrm{R}^{2}$ —coefficient of determination; MAPE—-mean absolute percentage error.

\begin{tabular}{lccccccccc}
\hline & \multicolumn{3}{c}{ RMS } & \multicolumn{3}{c}{$\mathbf{R}^{\mathbf{2}}$} & \multicolumn{3}{c}{ MAPE } \\
\hline & Train & Validation & Test & Train & Validation & Test & Train & Validation & Test \\
\hline Case 1 & 0.028 & 0.029 & 0.039 & 0.99 & 0.987 & 0.938 & 1.683 & 2.371 & 2.437 \\
Case 2 & 0.018 & 0.031 & 0.042 & 0.925 & 0.913 & 0.902 & 1.637 & 2.177 & 2.211 \\
Case 3 & 0.026 & 0.026 & 0.038 & 0.988 & 0.963 & 0.923 & 1.158 & 1.358 & 1.563 \\
Case 4 & 0.025 & 0.028 & 0.045 & 0.948 & 0.906 & 0.887 & 1.436 & 1.611 & 1.804 \\
Case 5 & 0.025 & 0.033 & 0.041 & 0.935 & 0.905 & 0.898 & 1.567 & 1.878 & 2.013 \\
\hline
\end{tabular}

The absolute errors of both the training and testing results of the ANN models are shown in Figures 12 and 13. The predicted value of the ANN models is very close to the test values by DTRT, especially the training results. In addition to a few points, the absolute errors are all within the interval of $[-0.1,0.1]$. The maximum relative error of the training sample is $4.7 \%$, and the average value is $0.7 \%$; the maximum relative error of the test sample is $5.6 \%$, and the average value is $1.1 \%$. Figure 14 shows the plots of the layered thermal conductivity of ZK04 predicted by the ANN models compared with the corresponding test values by DTRT. The predicted values of the ANN models fit the field test values well, which shows that using ANN models to predict layered thermal conductivity is feasible, and the prediction result is reliable. The prediction model of ANN is economical and time-saving relative to the DTRT test, and it can be further applied and promoted to provide a new idea for predicting thermal conductivity.

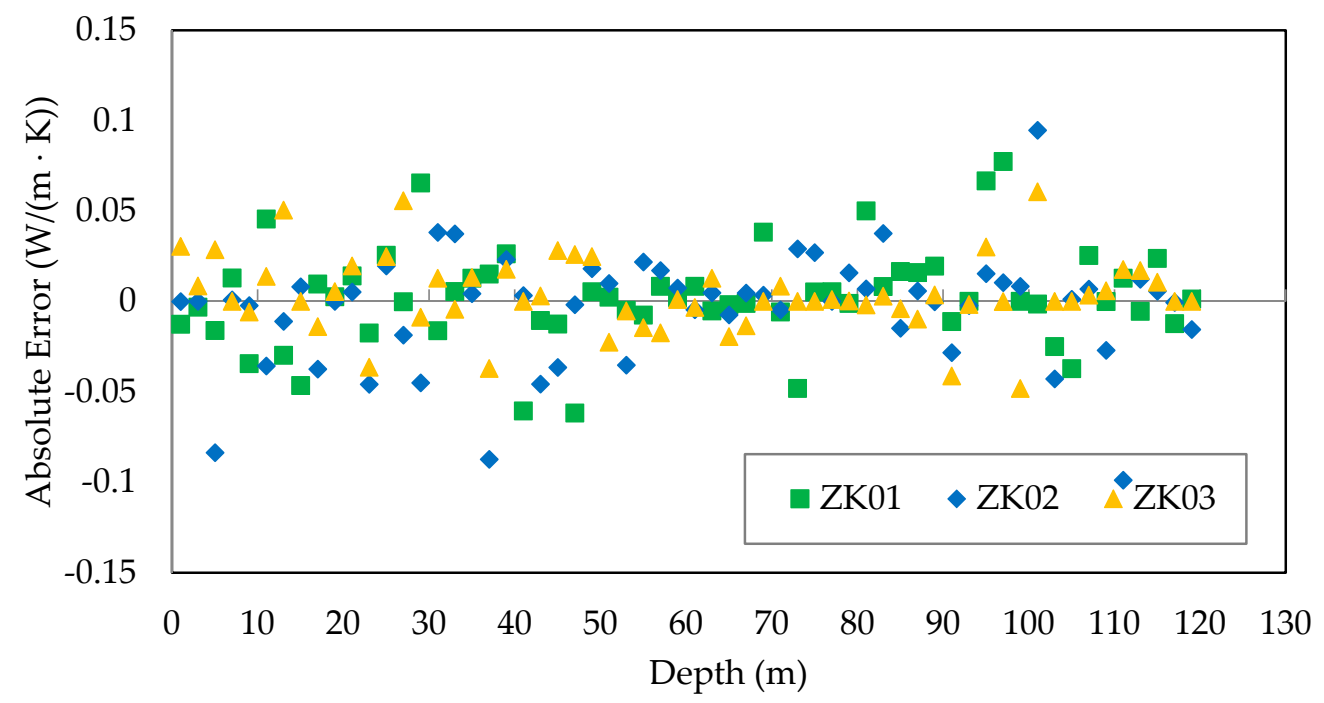

Figure 12. Absolute error of training results of ANN models. 


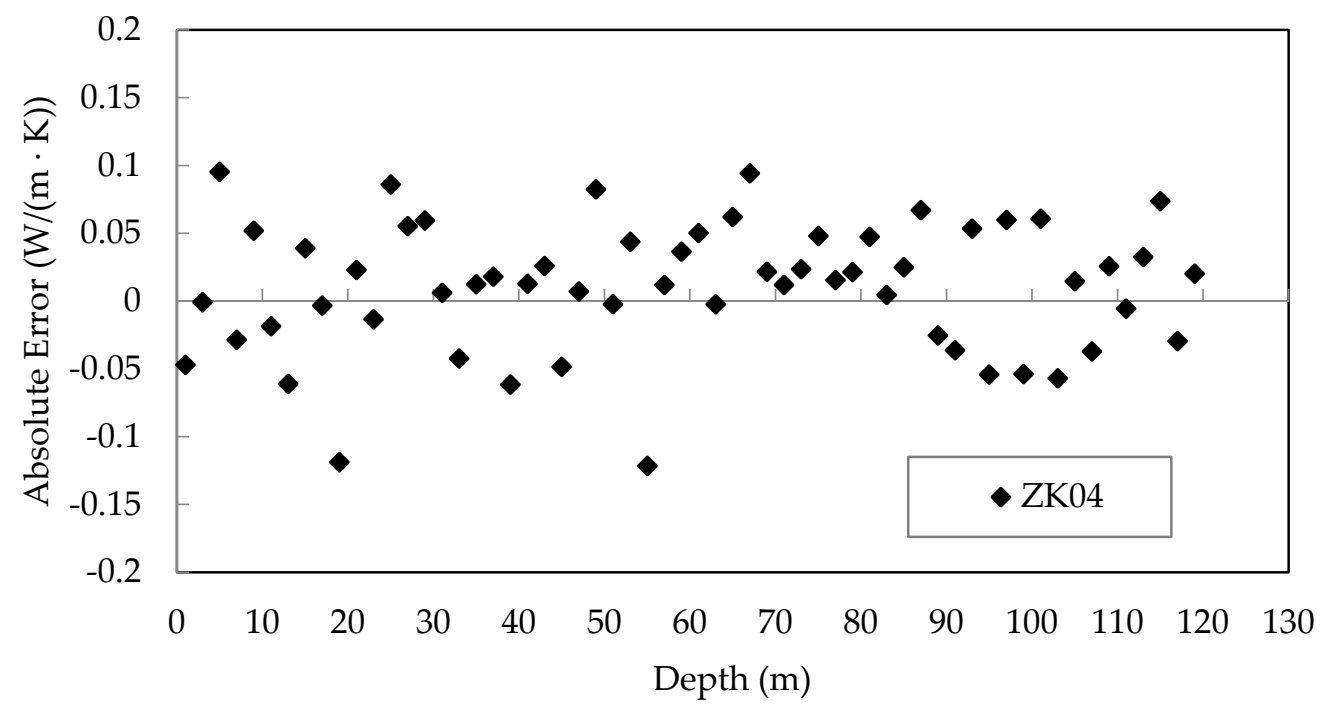

Figure 13. Absolute error of testing results of ANN models.

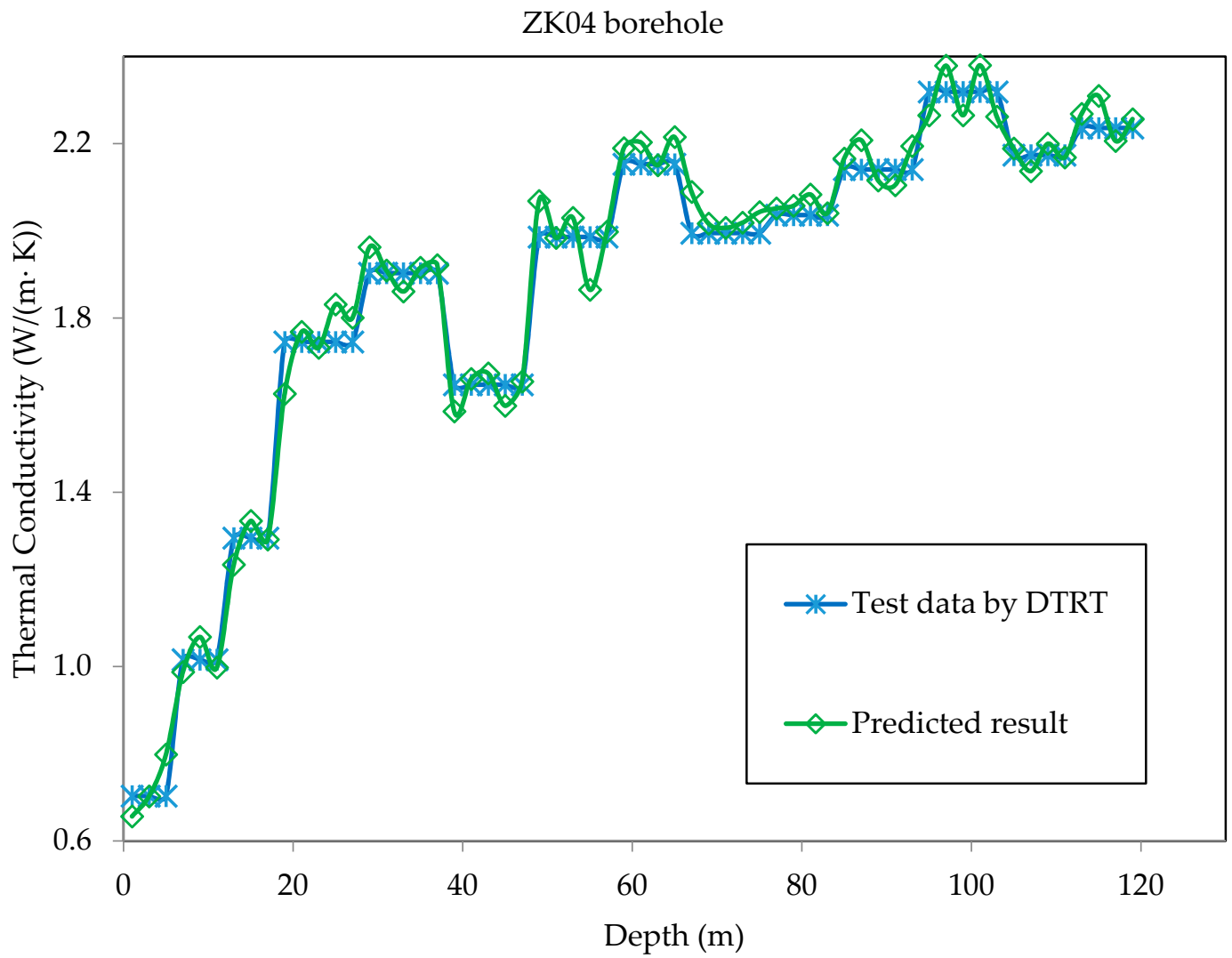

Figure 14. Prediction results of layered thermal conductivity for ZK04.

\section{Project Example 2}

\subsection{Project Overview of CYO2 Study Region}

In the CY01 field test area, the thermal physical tests were performed to apply GSHP. The tests involved two standard TRTs and 120 laboratory thermal physical tests and physical property tests of rock and soil samples for the ZK05 and ZK06 boreholes. Table A1 only shows the results of the laboratory tests of the ZK05 because of the volume of data. As can be seen from the table, the formation 
conditions of the CY01 and CY02 study regions are similar. Relative to the CY01 study region, the CY02 has a slightly higher water content, density, and thermal conductivity. The porosity of the CY02 is roughly the same as that of the CY01.

A heating power of $5600 \mathrm{~W}$ was constant during the TRTs, and hot water was imported to the pipe at not less than $1 \mathrm{~m}^{3} / \mathrm{h}$ from the water pump. The entire experiment experienced $48 \mathrm{~h}$ heating periods. Inlet and outlet temperature, flow rate, and heat power were recorded by the data acquisition system at an interval of $1 \mathrm{~min}$. The recordings of ZK05 are shown in Figures 15 and 16. The thermal physical parameters were obtained by interpreting the recordings with the line source model [17]. The calculated results are shown in Table 3.

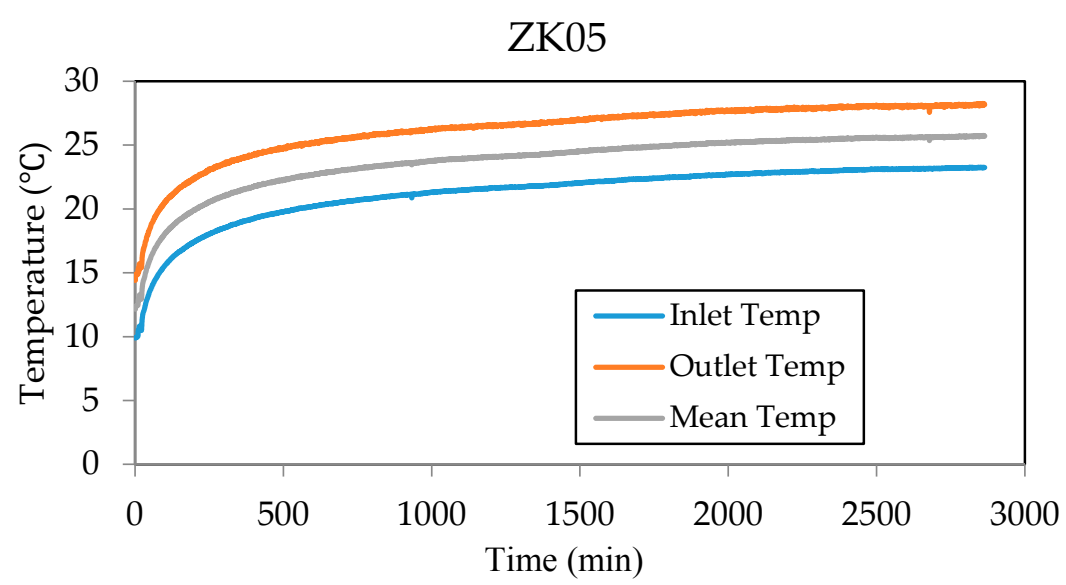

Figure 15. Inlet and outlet fluid temperatures during the test.

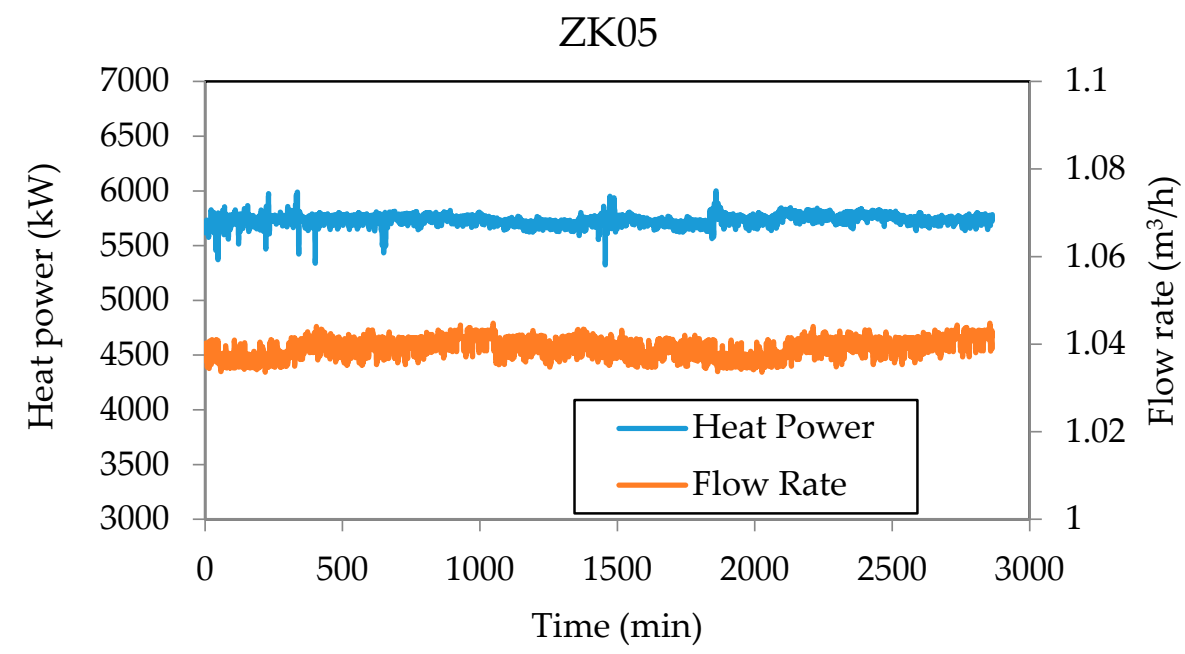

Figure 16. Heat power and fluid flow rate during the test. 
Table 3. The standard thermal response test (TRT) results.

\begin{tabular}{|c|c|c|c|}
\hline Borehole & ZK05 & & ZK06 \\
\hline Pipe depth (m) & & 120 & \\
\hline Type & & single-U & \\
\hline Initial temperature $\left({ }^{\circ} \mathrm{C}\right)$ & & 8.3 & \\
\hline Heating power $(\mathrm{W})$ & & 5600 & \\
\hline Thermal conductivity $(\mathrm{W} /(\mathrm{m} \cdot \mathrm{K}))$ & 1.786 & & 1.742 \\
\hline Volumetric specific heat capacity $\left(10^{6} \mathrm{~J} /\left(\mathrm{m}^{3} \cdot \mathrm{K}\right)\right)$ & 1.097 & & 1.253 \\
\hline Borehole thermal resistance $((\mathrm{m} \cdot \mathrm{K}) / \mathrm{W})$ & 0.116 & & 0.104 \\
\hline Thermal diffusivity $\left(10^{-6} \mathrm{~m}^{2} / \mathrm{s}\right)$ & 1.628 & & 1.511 \\
\hline
\end{tabular}

The thermal physical parameters in the CY02 study region were only determined by laboratory methods and standard TRT. The thermal conductivity by laboratory methods was often smaller than the true value, so it could not be directly adopted in designing a GSHP system. The thermal conductivity by the standard TRT was an average value, which was not accurate when applied to the GSHP system. Finding a suitable method to predict the layered thermal conductivity is thus necessary. The CY02 study region is located very near the CY01, and the geological conditions are similar based on the drilling data. Therefore, the ANN models of the CY01 can be used to predict the layered thermal conductivity for the CY02.

\subsection{Project Application}

Figures 17 and 18 shows the plots of the layered thermal conductivity of ZK05 and ZK06 predicted by the ANN models and the corresponding test values by the laboratory methods, respectively. The average values of the thermal conductivity of generalized five layers could be obtained (Table 4) based on the testing results of laboratory samples. Table 4 also shows the average values of the predicted layered thermal conductivity by the ANN models. Through calculation, the relative errors of laboratory tests and ANN prediction results are $47.8 \%, 20.6 \%, 21.8 \%, 16.6 \%$, and $26.3 \%$ for silty clay, mudstone, sandstone, silty mudstone, and fine sandstone, respectively. It can be seen that the difference between silty clay, sandstone, and fine sandstone is relatively larger than mudstone and silty mudstone. This is likely because the silty clay, sandstone, and fine sandstone are aquifers, the water content and the underground seepage conditions changes greatly during the sampling process. Therefore, the difference between field tests and laboratory tests should be larger. This is similar to the test results in the CY01 study area, which indicates that ANN prediction results of the CY02 study area are in accordance with this fact.

In addition, it is necessary to further verify the accuracy of ANN prediction results. Two key parameters for designing the GSHP system are the depth of the GHE and the thermal conductivity. The product of the two parameters can represent the heat exchanging capacity of the rock and soil layers. For the standard TRT,

$$
K=H \cdot \lambda
$$

where $H$ is the total depth of the borehole, $m$; and $\lambda$ is the thermal conductivity, $\mathrm{W} /(\mathrm{m} \cdot \mathrm{K})$.

For the ANN models, we can calculate the heat exchanging capacity by Equation (15), which shows that the product is obtained when the predicted thermal conductivity of each layer is multiplied by its depth, as represented by Equation (14). The calculated value should be equal to the theoretical result of the standard TRT.

$$
K=H \cdot \lambda^{*}=h_{1} \cdot \lambda_{1}+h_{2} \cdot \lambda_{2}+\cdots+h_{n} \cdot \lambda_{n}
$$

where $\lambda^{*}$ is the uniform predicted thermal conductivity, $\mathrm{W} /(\mathrm{m} \cdot \mathrm{K}) ; \lambda_{1}, \cdots, \lambda_{n}$ is the predicted thermal conductivity corresponding to each rock and soil layer, respectively, $\mathrm{W} /(\mathrm{m} \cdot \mathrm{K})$; and $h_{1}, \cdots, h_{n}$ are the depths of each rock and soil layer after generalization,m. For the laboratory methods, we can also 
calculate the heat exchanging capacity by Equation (15). The calculation results of the heat exchanging capacity are shown in Table 4.

The discrepancies between the standard TRT and the laboratory methods are $20.77 \%$ and $17.97 \%$ for ZK05 and ZK06, respectively. These results illustrate that the thermal physical parameters of the laboratory tests only reflect a part of the heat transfer capacity, which indicates a huge gap when compared with actual situations. The discrepancy between the standard TRT and the ANN models is $5.43 \%$ and $6.37 \%$ for ZK05 and ZK06, respectively. The calculated results show that the thermal physical parameters predicted by the ANN models could reflect the heat transfer capacity of the rock and soil layers. These findings indicate that the proposed method in this study is applicable, and the predicted layered thermal conductivity is convenient for engineering design.

Because the ANN models were established based on the CY01 study area, and the strata mainly consist of silty clay, mudstone, sandstone, silty mudstone, and fine sandstone. Therefore, the model has higher accuracy in predicting sites with similar formation conditions. However, the idea in this paper can be extended to other regions with different strata. We will continue to explore the suitability of ANN for predicting the layered thermal conductivity under other lithologic conditions.

Table 4. Average layered thermal conductivity obtained by ANN models, laboratory test, and the standard TRT.

\begin{tabular}{ccccccc}
\hline \multirow{2}{*}{ Layer Type } & \multicolumn{2}{c}{ Thermal Conductivity of ZK05 } & \multicolumn{3}{c}{ Thermal Conductivity of ZK06 } \\
(W/m·K) & \multicolumn{3}{c}{ (W/m) } & \\
\cline { 2 - 7 } & ANN & Laboratory & TRT & ANN & Laboratory & TRT \\
\hline silty clay & 1.060 & 0.582 & & 1.016 & 0.502 & \\
mudstone & 1.795 & 1.393 & & 1.780 & 1.445 & \\
sandstone & 2.090 & 1.602 & 1.786 & 1.994 & 1.591 & 1.742 \\
$\begin{array}{c}\text { fine sandstone } \\
\text { silty mudstone }\end{array}$ & 1.982 & 1.598 & & 1.933 & 1.667 & \\
$\begin{array}{c}\text { Heat exchanging } \\
\text { capacity (W/K) }\end{array}$ & 2.306 & 1.715 & & 2.287 & 1.672 & \\
\hline
\end{tabular}

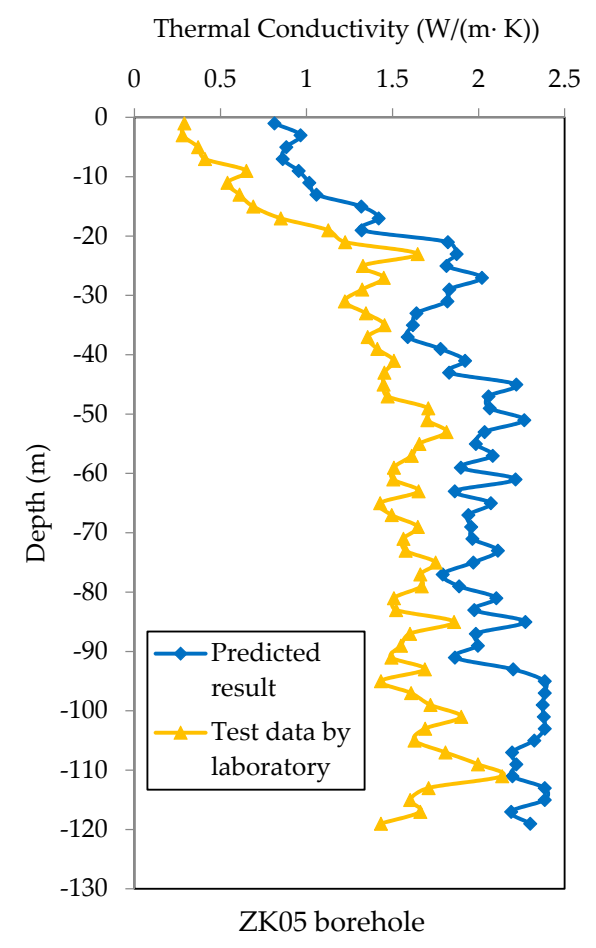

Figure 17. Prediction results of layered thermal conductivity for ZK05. 


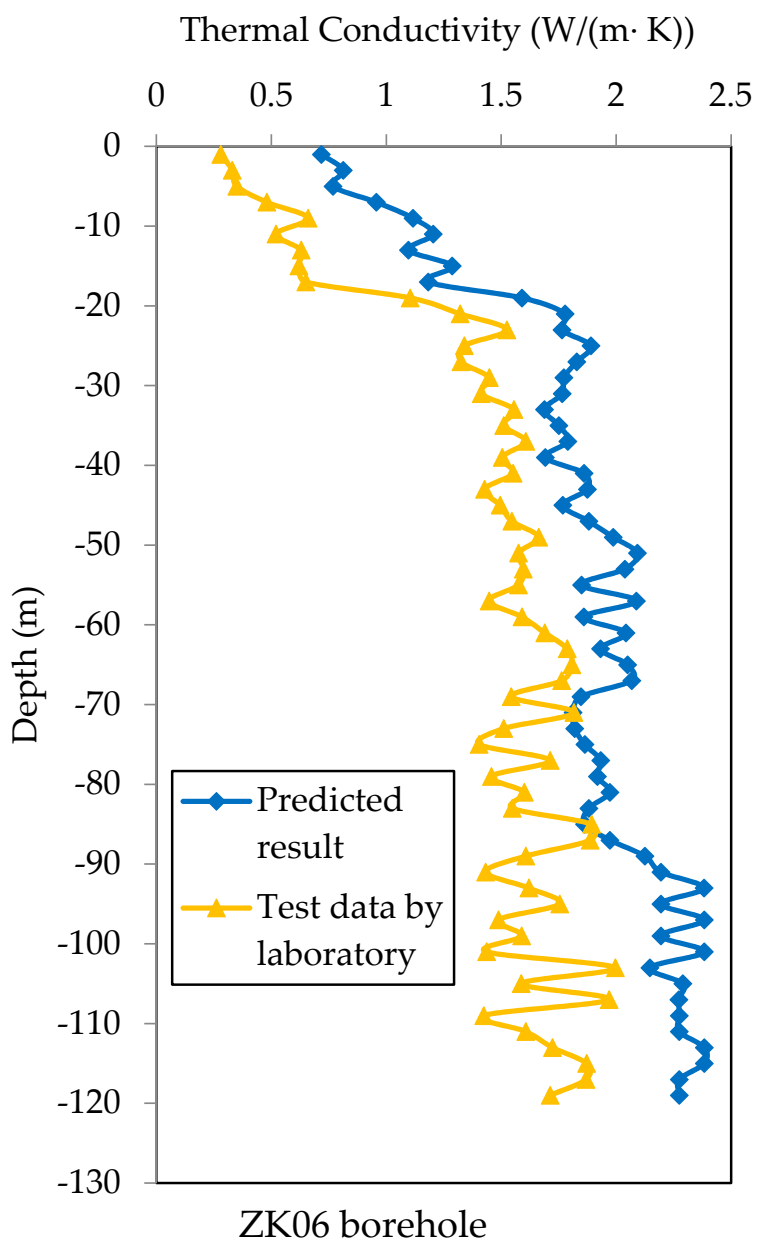

Figure 18. Prediction results of layered thermal conductivity for ZK06.

\section{Conclusions}

In this study, the thermophysical parameters for two study regions in Changchun district are determined through the standard TRT, DTRT, and laboratory tests. The main affect factors of the thermal conductivity are determined according to the test results and previous research data. Then, the main factors are used to predict the layered thermal conductivity based on ANN models. The main findings of this study can be summarized as follows:

1. In the study region, the average temperature is $8.6^{\circ} \mathrm{C}$ over the entire range of the ground within $120 \mathrm{~m}$, except for the changing temperature layer, and the geothermal gradient is approximately $3{ }^{\circ} \mathrm{C} / 100 \mathrm{~m}$ from $40 \mathrm{~m}$ to $120 \mathrm{~m}$.

2. The average layered thermal conductivity values obtained by DTRT are $0.979,1.768,2.106,2.042$, and $2.313 \mathrm{~W} /(\mathrm{m} \cdot \mathrm{K})$ for silty clay, mudstone, sandstone, silty mudstone, and fine sandstone, respectively. The corresponding average layered thermal conductivity values obtained by laboratory are $0.520,1.358,1.647,1.837$, and $1.915 \mathrm{~W} /(\mathrm{m} \cdot \mathrm{K})$. These values are caused by the changes in water content and space environment during sampling, especially the groundwater seepage. The measured values of layered thermal conductivity by the laboratory are all less than those by by DTRT.

3. Based on the analyses of the test results in the CY01 study region and previous research data, the main factors influencing the conductivity results are water content, porosity, and density, which can be used as input variables for the ANN models. 
4. BP neural network models are established to predict the layered thermal conductivity for the CY01 study region. The prediction accuracy is measured by $\mathrm{R}^{2}$, RMS, and MAPE. The results show that the average MAPE values are 1.496, 1.879, and 2.006 for the training, validation, and test sets, respectively. The average RMS values of the training, validation, and test sets are 0.0244 , 0.0294 , and 0.0410 , respectively. The average $\mathrm{R}^{2}$ values of the training, validation, and test sets are $0.9692,0.9448$, and 0.9162 , respectively. The results demonstrate that the use of ANN for predicting the layered thermal conductivity has high prediction accuracy.

5. For the CY01 study region, the absolute errors between the test values by DTRT and the predicted value of the ANN models are all within the interval of $[-0.1,0.1]$. The maximum relative error of the training sample is $4.7 \%$, and the average value is $0.7 \%$. The maximum relative error of the test sample is $5.6 \%$, and the average value is $1.1 \%$.

6. For the CY02 study region, the discrepancy of the heat exchanging capacity between the standard TRT and the laboratory methods is $20.77 \%$ and $17.97 \%$ for ZK05 and ZK06, respectively. The discrepancy of the heat exchanging capacity between the standard TRT and the ANN models is $5.43 \%$ and $6.37 \%$ for ZK05 and ZK06, respectively. The results demonstrate that the proposed method of ANN is feasible, and the results are satisfactory.

7. Compared with DTRT, the prediction model of ANN is more economical and time-saving. Furthermore, the model has higher accuracy in predicting sites with similar formation conditions. The method can be extended to other regions with different strata. As for the next step, we will continue to explore the suitability of ANN for predicting the layered thermal conductivity under other lithologic conditions.

Author Contributions: Y.Z. and Z.H. conceived and designed the experiments; L.Z. and S.H. performed the experiments; Z.L., L.Z. and Y.X. analyzed the data; Z.Y. contributed reagents/materials/analysis tools; L.Z. wrote the paper.

Acknowledgments: This study was supported by the Natural Science Foundation of China (Grant Nos. 41602243 \& 41772238), the New Energy Program of Jilin Province (NO. SXGJSF2017-5).

Conflicts of Interest: The authors declare no conflicts of interest.

\section{Nomenclature}

$\omega_{i j} \quad$ the weight between the input and hidden neurons

$\omega_{j k} \quad$ the weight between the hidden and output neurons

$x_{i} \quad$ the value of the input

$H_{j} \quad$ the value of the output for hidden nodes

$\mathrm{O}_{k} \quad$ the value of the output for output nodes

$m$ the number of neurons of the output layer

$a_{j} \quad$ the bias weight between the input and hidden neurons

$b_{k} \quad$ the bias weight between the hidden and output neurons

$e_{k} \quad$ the prediction error

$Y_{k} \quad$ the expected value

$\eta \quad$ the learning rate

$\lambda_{\text {test }, i} \quad$ the testing value

$\lambda_{\text {pre }, i} \quad$ he calculated value, $\mathrm{W} / \mathrm{m} \cdot \mathrm{K}$

the number of neurons of the hidden layer

$n$ the number of inputs of neuron

$N \quad$ the number of samples

$\mathrm{K}$ the heat exchanging capacity, $\mathrm{W} / \mathrm{K}$

$H$ the total depth of the borehole, $\mathrm{m}$ 
$\lambda \quad$ the thermal conductivity, $\mathrm{W} / \mathrm{m} \cdot \mathrm{K}$

$\lambda^{*} \quad$ the uniform predicted thermal conductivity, $\mathrm{W} / \mathrm{m} \cdot \mathrm{K}$

$\lambda_{1}, \cdots, \lambda_{n} \quad$ the predicted thermal conductivity corresponding to each rock and soil layer, respectively,

$h_{1}, \cdots, h_{n} \quad$ the depths of each rock and soil layer after generalization, $\mathrm{m}$

RMS the root mean squared error

$R^{2} \quad$ the coefficient of determination

$M A P E \quad$ mean absolute percentage error

\section{Appendix A}

Table A1. Testing results of the laboratory tests.

\begin{tabular}{|c|c|c|c|c|c|c|c|}
\hline \multirow[b]{2}{*}{$\begin{array}{l}\text { Sample } \\
\text { Name }\end{array}$} & \multirow[b]{2}{*}{$\begin{array}{c}\text { Sample } \\
\text { Depth (m) }\end{array}$} & \multicolumn{3}{|c|}{ Physical Properties } & \multicolumn{3}{|c|}{ Thermal Physical Properties } \\
\hline & & $\begin{array}{c}\text { Water } \\
\text { Content } \\
\%\end{array}$ & $\begin{array}{c}\text { Density } \\
\mathrm{kg} / \mathrm{m}^{3}\end{array}$ & Porosity & $\begin{array}{l}\text { Thermal } \\
\text { Conductivity } \\
\mathrm{W} /(\mathrm{m} \cdot \mathrm{K})\end{array}$ & $\begin{array}{c}\text { Mass Specific } \\
\text { Heat Capacity } \\
\mathrm{kJ} /(\mathrm{kg} \cdot \mathrm{K})\end{array}$ & $\begin{array}{l}\text { Thermal } \\
\text { Diffusivity } \\
10^{-6} \mathrm{~m}^{2} / \mathrm{s}\end{array}$ \\
\hline silty clay & $2.0-2.2$ & 22.8 & 2070 & 0.987 & 0.29 & 1.264 & 0.116 \\
\hline silty clay & $4.0-4.2$ & 24 & 2060 & 0.921 & 0.28 & 1.212 & 0.113 \\
\hline silty clay & $6.0-6.2$ & 27.3 & 2040 & 0.851 & 0.37 & 1.203 & 0.147 \\
\hline silty clay & $8.0-8.2$ & 21.9 & 2020 & 0.729 & 0.41 & 1.145 & 0.168 \\
\hline silty clay & $10.0-10.2$ & 23 & 2000 & 0.756 & 0.65 & 1.056 & 0.272 \\
\hline silty clay & $12.0-12.2$ & 25.2 & 1920 & 0.699 & 0.54 & 1.099 & 0.237 \\
\hline silty clay & $14.0-14.2$ & 24.6 & 1850 & 0.839 & 0.61 & 1.045 & 0.512 \\
\hline silty clay & $16.0-16.2$ & 20 & 1860 & 0.671 & 0.69 & 1.023 & 0.377 \\
\hline silty clay & $18.0-18.2$ & 21.9 & 1850 & 0.779 & 0.85 & 1.073 & 0.609 \\
\hline mudstone & $20.0-20.2$ & 19.2 & 1920 & 0.648 & 1.126 & 1.097 & 0.641 \\
\hline mudstone & $22.0-22.2$ & 18.1 & 1970 & 0.509 & 1.224 & 0.977 & 0.651 \\
\hline mudstone & $24.0-24.2$ & 13.9 & 1990 & 0.451 & 1.645 & 1.054 & 1.563 \\
\hline mudstone & $26.0-26.2$ & 13 & 1970 & 0.303 & 1.328 & 0.983 & 0.723 \\
\hline mudstone & $28.0-28.2$ & 15.2 & 1940 & 0.384 & 1.448 & 0.986 & 0.837 \\
\hline mudstone & $30.0-30.2$ & 14.8 & 1990 & 0.398 & 1.323 & 1.373 & 0.738 \\
\hline mudstone & $32.0-32.2$ & 11.9 & 2040 & 0.283 & 1.222 & 1.023 & 0.694 \\
\hline mudstone & $34.0-34.2$ & 13.1 & 2010 & 0.271 & 1.345 & 1.035 & 0.545 \\
\hline mudstone & $36.0-36.2$ & 11.9 & 2100 & 0.246 & 1.453 & 0.971 & 0.779 \\
\hline mudstone & $38.0-38.2$ & 15.7 & 2080 & 0.283 & 1.355 & 0.769 & 0.709 \\
\hline mudstone & $40.0-40.2$ & 17.5 & 2000 & 0.359 & 1.411 & 0.993 & 0.786 \\
\hline mudstone & $42.0-42.2$ & 15.1 & 1980 & 0.368 & 1.507 & 0.964 & 0.904 \\
\hline mudstone & $44.0-44.2$ & 14.1 & 1980 & 0.371 & 1.452 & 0.694 & 0.647 \\
\hline mudstone & $46.0-46.2$ & 18.6 & 1960 & 0.487 & 1.447 & 0.973 & 0.828 \\
\hline mudstone & $48.0-48.2$ & 18.8 & 2050 & 0.403 & 1.471 & 0.976 & 0.753 \\
\hline sandstone & $50.0-50.2$ & 22.5 & 2150 & 0.435 & 1.707 & 1.015 & 0.931 \\
\hline sandstone & $52.0-52.2$ & 19.7 & 2160 & 0.521 & 1.702 & 1.304 & 0.957 \\
\hline sandstone & $54.0-54.2$ & 18.4 & 2090 & 0.409 & 1.813 & 1.036 & 0.623 \\
\hline sandstone & $56.0-56.2$ & 19.6 & 2150 & 0.386 & 1.655 & 1.075 & 0.752 \\
\hline sandstone & $58.0-58.2$ & 18.7 & 2100 & 0.468 & 1.611 & 0.975 & 0.896 \\
\hline sandstone & $60.0-60.2$ & 19.1 & 2180 & 0.481 & 1.507 & 0.942 & 0.695 \\
\hline mudstone & $62.0-62.2$ & 15.9 & 2110 & 0.445 & 1.504 & 0.955 & 0.835 \\
\hline mudstone & $64.0-64.2$ & 10.8 & 2000 & 0.387 & 1.651 & 1.073 & 0.681 \\
\hline mudstone & $66.0-66.2$ & 8.6 & 1990 & 0.306 & 1.427 & 0.968 & 0.494 \\
\hline mudstone & $68.0-68.2$ & 9.6 & 2010 & 0.354 & 1.495 & 0.939 & 0.719 \\
\hline mudstone & $70.0-70.2$ & 10.7 & 1995 & 0.321 & 1.646 & 0.873 & 0.905 \\
\hline mudstone & $72.0-72.2$ & 8.1 & 2040 & 0.346 & 1.563 & 0.861 & 0.780 \\
\hline mudstone & $74.0-74.2$ & 10.8 & 2090 & 0.255 & 1.575 & 1.015 & 0.678 \\
\hline mudstone & $76.0-76.2$ & 8.4 & 2060 & 0.346 & 1.75 & 1.092 & 0.892 \\
\hline mudstone & $78.0-78.2$ & 9.6 & 2050 & 0.300 & 1.661 & 0.872 & 1.026 \\
\hline mudstone & $80.0-80.2$ & 10.4 & 2095 & 0.401 & 1.669 & 1.053 & 0.883 \\
\hline mudstone & $82.0-82.2$ & 11.2 & 2075 & 0.261 & 1.507 & 0.835 & 0.461 \\
\hline
\end{tabular}


Table A1. Cont.

\begin{tabular}{|c|c|c|c|c|c|c|c|}
\hline \multirow[b]{2}{*}{$\begin{array}{l}\text { Sample } \\
\text { Name }\end{array}$} & \multirow[b]{2}{*}{$\begin{array}{c}\text { Sample } \\
\text { Depth (m) }\end{array}$} & \multicolumn{3}{|c|}{ Physical Properties } & \multicolumn{3}{|c|}{ Thermal Physical Properties } \\
\hline & & $\begin{array}{c}\text { Water } \\
\text { Content } \\
\%\end{array}$ & $\begin{array}{l}\text { Density } \\
\mathrm{kg} / \mathrm{m}^{3}\end{array}$ & Porosity & $\begin{array}{l}\text { Thermal } \\
\text { Conductivity } \\
\mathrm{W} /(\mathrm{m} \cdot \mathrm{K})\end{array}$ & $\begin{array}{l}\text { Mass Specific } \\
\text { Heat Capacity } \\
\mathrm{kJ} /(\mathrm{kg} \cdot \mathrm{K})\end{array}$ & $\begin{array}{l}\text { Thermal } \\
\text { Diffusivity } \\
10^{-6} \mathrm{~m}^{2} / \mathrm{s}\end{array}$ \\
\hline mudstone & $84.0-84.2$ & 9.9 & 2085 & 0.316 & 1.52 & 0.964 & 0.603 \\
\hline sandstone & $86.0-86.2$ & 12.5 & 2000 & 0.300 & 1.857 & 0.835 & 0.833 \\
\hline sandstone & $88.0-88.2$ & 12.8 & 1995 & 0.351 & 1.601 & 0.852 & 0.851 \\
\hline sandstone & $90.0-90.2$ & 8.1 & 2025 & 0.332 & 1.548 & 0.955 & 0.737 \\
\hline mudstone & $92.0-92.2$ & 12 & 2145 & 0.398 & 1.493 & 1.156 & 0.714 \\
\hline mudstone & $94.0-94.2$ & 13.1 & 2210 & 0.425 & 1.687 & 1.056 & 0.941 \\
\hline sandstone & $96.0-96.2$ & 15.3 & 2240 & 0.445 & 1.432 & 1.038 & 0.787 \\
\hline mudstone & $98.0-98.2$ & 16.3 & 2150 & 0.451 & 1.607 & 1.202 & 0.810 \\
\hline mudstone & $100.0-100.2$ & 13.1 & 2220 & 0.439 & 1.72 & 0.932 & 0.929 \\
\hline sandstone & $102.0-102.2$ & 14.3 & 2200 & 0.513 & 1.899 & 1.125 & 0.984 \\
\hline sandstone & $104.0-104.2$ & 15.4 & 2260 & 0.507 & 1.689 & 0.78 & 0.902 \\
\hline sandstone & $106.0-106.2$ & 12.9 & 2150 & 0.498 & 1.627 & 1.134 & 0.971 \\
\hline sandstone & $108.0-108.2$ & 12.5 & 2250 & 0.376 & 1.807 & 0.922 & 0.932 \\
\hline sandstone & $110.0-110.2$ & 11.9 & 2230 & 0.437 & 1.996 & 1.064 & 0.732 \\
\hline sandstone & $112.0-112.2$ & 16.8 & 2140 & 0.399 & 2.137 & 0.954 & 1.397 \\
\hline sandstone & $114.0-114.2$ & 16.2 & 2260 & 0.499 & 1.709 & 0.943 & 0.794 \\
\hline sandstone & $116.0-116.2$ & 18.6 & 2220 & 0.419 & 1.602 & 0.978 & 0.600 \\
\hline sandstone & $118.0-118.2$ & 11.2 & 2230 & 0.361 & 1.661 & 0.83 & 0.663 \\
\hline sandstone & $120.0-120.2$ & 11.5 & 2290 & 0.432 & 1.432 & 0.989 & 0.558 \\
\hline
\end{tabular}

\section{References}

1. Mensah, K.; Jang, Y.S.; Choi, J.M. Assessment of design strategies in a ground source heat pump system. Energy Build. 2017, 138, 301-308. [CrossRef]

2. Soriano, G.; Espinoza, T.; Villanueva, R.; Gonzalez, I.; Montero, A.; Cornejo, M.; Lopez, K. Thermal geological model of the city of Guayaquil, Ecuador. Geothermics 2017, 66, 101-109. [CrossRef]

3. Guo, M.; Diao, N.; Man, Y.; Fang, Z. Research and development of the hybrid ground-coupled heat pump technology in China. Renew. Energy 2016, 87, 1033-1044. [CrossRef]

4. Franco, A.; Moffat, R.; Toledo, M.; Herrera, P. Numerical sensitivity analysis of thermal response tests (TRT) in energy piles. Renew. Energy 2016, 86, 985-992. [CrossRef]

5. Dehkordi, S.E.; Schincariol, R.A.; Reitsma, S. Thermal performance of a tight borehole heat exchanger. Renew. Energy 2015, 83, 698-704. [CrossRef]

6. Zheng, W.; Zhang, H.; You, S.; Ye, T. The Thermal Characteristics of a Helical Coil Heat Exchanger for Seawater-source Heat Pump in Cold Winter. Procedia Eng. 2016, 146, 549-558. [CrossRef]

7. Kharseh, M.; Al-Khawaja, M.; Suleiman, M.T. Potential of ground source heat pump systems in cooling-dominated environments: Residential buildings. Geothermics 2015, 57, 104-110. [CrossRef]

8. Herrera, C.; Nellis, G.; Reindl, D.; Klein, S.; Tinjum, J.M.; McDaniel, A. Use of a fiber optic distributed temperature sensing system for thermal response testing of ground-coupled heat exchangers. Geothermics 2018, 71, 331-338. [CrossRef]

9. Zhang, Y.J.; Zhang, J.N.; Yu, Z.W.; Guo, L.L.; Hao, S.R. Analysis of the influence of different groundwater flow conditions on the thermal response test in Tangshan. Environ. Earth Sci. 2016, 75, 1444. [CrossRef]

10. Sakata, Y.; Katsura, T.; Nagano, K. Multilayer-concept thermal response test: Measurement and analysis methodologies with a case study. Geothermics 2018, 71, 178-186. [CrossRef]

11. Gao, P.; Zhang, Y.J.; Yu, Z.W.; Fang, J.T.; Zhang, Q. Correlation study of shallow layer rock and soil thermal physical tests in laboratory and field. Geothermics 2015, 53, 508-516. [CrossRef]

12. Zhang, Y.J.; Gao, P.; Yu, Z.W.; Fang, J.T.; Li, C. Characteristics of ground thermal properties in Harbin, China. Energy Build. 2014, 69, 251-259. [CrossRef]

13. Zhang, Q.; Zhang, Y.J.; Gao, P.; Yu, Z.W. Effect of natural cold source on groundwater source heat pump according to laboratory and field geotechnical thermal physical tests. Energy Build. 2014, 84, 557-566. [CrossRef] 
14. Bertermann, D.; Klug, H.; Morper-Busch, L. A pan-European planning basis for estimating the very shallow geothermal energy potentials. Renew. Energy 2015, 75, 335-347. [CrossRef]

15. Zhang, C.X.; Guo, Z.J.; Liu, Y.F.; Cong, X.C.; Peng, D.G. A review on thermal response test of ground-coupled heat pump systems. Renew. Sustain. Energy Rev. 2014, 40, 851-867. [CrossRef]

16. Mogensen, P. Fluid to duct wall heat transfer in duct system heat storages. In Proceedings of the International Conference on Subsurface Heat Storage in Theory and Practice, Stockholm, Sweden, 6-8 June 1983; pp. 1652-6571.

17. Ingersoll, L.R.; Plass, H.J. Theory of the ground pipe heat source for the heat pump. Heat. Pip. Air Cond. 1948, 20, 119-122.

18. Cao, D.; Shia, B.; Ii, S.P.L.; Gong, X.; Zhu, H.H.; Wei, G.Q.; Yang, L.M. Investigation of the influence of soil moisture on thermal response tests using active distributed temperature sensing (A-DTS) technology. Energy Build. 2018, 173, 239-251. [CrossRef]

19. Lee, C.K. Effects of multiple ground layers on thermal response test analysis and ground-source heat pump simulation. Appl. Energy 2011, 88, 4405-4410. [CrossRef]

20. Fujii, H.; Okubo, H.; Itoi, R. Thermal response tests using optical fiber thermometers. Trans. Geotherm. Resour. Counc. 2006, 30, 545-551.

21. Fujii, H.; Okubo, H.; Nishi, K.; Itoi, R.; Ohyama, K.; Shibata, K. An improved thermal response test for U-tube ground heat exchanger based on optical fiber thermometers. Geothermics 2009, 38, 399-406. [CrossRef]

22. Acuña, J.; Mogensen, P.; Palm, B. Distributed thermal response test on a u-pipe borehole heat exchanger. Appl. Energy 2009, 109. [CrossRef]

23. Zhang, Y.J.; Yu, Z.W.; Huang, R.; Wu, G.; Hu, J.H. Measurement of thermal conductivity and temperature effect of geotechnical materials. Chin. J. Geotech. Eng. 2009, 31, 213-217. (In Chinese)

24. Cho, W.J.; Kwon, S.; Choi, J.W. The thermal conductivity for granite with various water contents. Eng. Geol. 2009, 107, 167-171. [CrossRef]

25. Cho, W.J.; Kwon, S. Estimation of the thermal properties for partially saturated granite. Eng. Geol. 2010, 115, 132-138. [CrossRef]

26. Alishaev, M.G.; Abdulagatov, I.M.; Abdulagatova, Z.Z. Effective thermal conductivity of fluid-saturated rocks: Experiment and modeling. Eng. Geol. 2012, 135-136, 24-39. [CrossRef]

27. Zhang, Y.J.; Hao, S.R.; Yu, Z.W.; Fang, J.T.; Zhang, J.N.; Yu, X.M. Comparison of test methods for shallow layered rock thermal conductivity between in situ distributed thermal response tests and laboratory test based on drilling in northeast China. Energy Build. 2018, 173, 634-648. [CrossRef]

28. Arcaklioğlu, E.; Erişen, A.; Yilmaz, R. Artificial neural network analysis of heat pumps using refrigerant mixtures. Energy Convers. Manag. 2004, 45, 1917-1929. [CrossRef]

29. Kumar, R.; Aggarwal, R.K.; Sharma, J.D. Energy analysis of a building using artificial neural network: A review. Energy Build. 2013, 65, 352-358. [CrossRef]

30. Esen, H.; Inalli, M.; Sengur, A.; Esen, M. Modelling a ground-coupled heat pump system using adaptive neuro-fuzzy inference systems. Int. J. Refrig. 2008, 31, 65-74. [CrossRef]

31. Esen, H.; Inalli, M.; Sengur, A.; Esen, M. Modeling a ground-coupled heat pump system by a support vector machine. Renew. Energy 2008, 33, 1814-1823. [CrossRef]

32. Esen, H.; Inalli, M.; Sengur, A.; Esen, M. Performance prediction of a groundcoupled heat pump system using artificial neural networks. Expert Syst. Appl. 2008, 35, 1940-1948. [CrossRef]

33. Esen, H.; Inalli, M. Modelling of a vertical ground coupled heat pump system by using artificial neural networks. Expert Syst. Appl. 2009, 36, 10229-10238. [CrossRef]

34. Fannou, J.L.C.; Rousseau, C.; Lamarche, L.; Kajl, S. Modeling of a direct expansion geothermal heat pump using artificialneural networks. Energy Build. 2014, 81, 381-390. [CrossRef]

35. Gang, W.J.; Wang, J.B. Predictive ANN models of ground heat exchanger for the control. Appl. Energy 2013, 112, 1146-1153. [CrossRef]

36. Gang, W.J.; Wang, J.B.; Wang, S.W. Performance analysis of hybrid ground source heat pump systems based on ANN predictive control of hybrid ground source heat pump systems. Appl. Energy 2014, 136, 1138-1144. [CrossRef]

37. Sang, K.P.; Moon, H.J.; Min, K.C.; Hwang, C.; Kim, S. Application of a multiple linear regression and an artificial neural network model for the heating performance analysis and hourly prediction of a large-scale ground source heat pump system. Energy Build. 2018, 165, 206-215. 
38. Fu, Z.Y.; Su, X.J. The suitability estimation and the prospect analysis of the development and utilization of buried-pipe ground source heat pump system in Changchun. Jilin Geol. 2017, 36, 39-41+47. (In Chinese)

39. Popov, Y.A.; Berezin, V.; Semionov, V.G.; Korosteliov, V.M. Complex detail investigations of the thermal properties of rocks on the basis of a moving point source. Izv. Phys. Solid Earth 1985, 21, 64-70.

40. Kallio, J.; Leppäharju, N.; Martinkauppi, I.; Nousiainen, M. Geoenergy research and its utilization in Finland. Geol. Surv. Finl. 2011, 49, 179-185.

41. Grattan, K.T.V.; Sun, T. Fiber optic sensor technology: An overview. Sens. Actuators A Phys. 2000, 82, 40-61. [CrossRef]

42. Abu-Hamdeh, H.N. Thermal properties of soils as affected by density and water content. Biosyst. Eng. 2003, 86, 97-102. [CrossRef]

43. Abuel-Naga, H.; Bergado, D.T.; Bouazza, A.; Pender, M. Thermal conductivity of soft Bankok clay from laboratory and field measurements. Eng. Geol. 2009, 105, 211-219. [CrossRef]

44. Haykin, S. Neural Networks: A Comprehensive Foundation, 2nd ed.; Pearson Education: Cranbury, NJ, USA, 1998.

45. Bowden, G.J.; Dandy, G.C.; Maier, H.R. Input determination for neural network models in water resources applications. Part 1-Background and Methodology. J. Hydrol. 2005, 301, 93-107. [CrossRef]

(C) 2018 by the authors. Licensee MDPI, Basel, Switzerland. This article is an open access article distributed under the terms and conditions of the Creative Commons Attribution (CC BY) license (http:/ / creativecommons.org/licenses/by/4.0/). 